\title{
AMERICAN RHEUMATISM ASSOCIATION
}

\section{PROCEEDINGS OF THE ANNUAL MEETING, 1954}

The annual meeting of the American Rheumatism Association was held at San Francisco, California, on June 18 and 19, 1954, under the presidency of Dr. Charles Ragan of New York. The presidential address, the interim report of the A.R.A. Cooperative Study of Cortisone Therapy, and abstracts of thirty papers with the discussions thereon are printed below.*

\section{Presidential Address}

BY

\section{Charles Ragan}

President, American Rheumatism Association,

\section{3-54}

Since the end of the second world war, the American Rheumatism Association has experienced a phenomenal growth in membership, in total number as well as in those participating actively at meetings. The physical size of the programme has grown, and it seems fair to say, without false pride, that the character of the programme has improved remarkably. The papers presented show more interest in basic problems and an increasingly careful evaluation of therapeutic agents. Young men have entered the field in larger numbers than could have been anticipated in the past, and in many instances, through support from the United States Public Health Service or the Arthritis and Rheumatism Foundation, they have provided themselves with a solid background of basic science upon which to build in the future. This we may regard as sound achievement. On the other side of the ledger, we have only to look at one of our major problemsrheumatoid arthritis - to realize that we have yet a long way to go. We continue to be in the dark concerning the origin and progression of this disease, and its course may only be predicted on a statistical basis, although our knowledge of the tissues and the changes induced by the disease has unquestionably advanced. There is, I believe, reason for this dichotomy. It is obvious that no one has a clear-cut

* There were also panel discussions on "Hormones in Rheumatic Disease" (Moderator: R. H. Freyberg) and "Rehabilitation of the Arthritic Patient" (Moderator: E. W. Lowman). idea for a direct approach to the core of the problem $\frac{\widehat{\Phi}}{\Omega}$ of rheumatoid arthritis, and investigation has, perforce, been pursued at the periphery through ${ }^{\text {Cs }}$ indirect paths.

So much for the past. What directions should we $\overrightarrow{-}$ take? We, in the American Rheumatism Associa- $\omega$ tion, have two aims in our efforts to do the best for@ our patients: to increase our knowledge, and to add? to the number of physicians competent to carry out $\vec{\omega}$ this care. To achieve this, new men of competence, $\stackrel{+}{\dot{\omega}}$ dedication, integrity, and originality are our crying $\stackrel{+}{+}$ and continuing need. A young man in medicine is $\mathrm{O}$ attracted to some particular area by natural interest, by the possibility of advancing knowledge, or $\vec{\square}$ perhaps unfortunately by the chance of assured $\mathbb{\Phi}$ security. The popular and fashionable areas of $\frac{\mathbb{Q}}{3}$ interest in the past have been largely those in which answers might be readily obtained by the investigator ${ }^{-}$ or in which the clinician might reasonably anticipate $\overrightarrow{0}$ a prompt and successful resolution of the patiento problems. For us in this Association, there appearito be few areas of research in which a quick answ ro can be foreseen by the investigator; the clinician confronted with the management of a rheumatico problem is aware that he faces long periods of sus- $\frac{\text { D }}{\mathrm{D}}$ tained and often frustrating effort. Thus, there are $\overrightarrow{\vec{T}}$ currently no easy answers to our questions, either in the field of investigation or in clinical management. $\frac{3}{5}$ The gratifications derived from the care of the patient with a protracted illness are intangible, and research in which one nibbles away at the periphery $\frac{\tilde{a}}{2}$ of a clinical problem seldom yields the pleasure which comes from the direct conquest of disease. The 3 . field of rheumatism does not much appeal to young men, in contrast to such a specialty as haematology -in which recent rapid progress has opened upo alluring vistas.

The roundabout attack on our problems, en- $-\frac{D}{0}$ forced by necessity, has led to another difficulty in the recruitment of younger men. As I have said, theor clinical care of the rheumatic patient is not easy, and N to be adept in it, one frequently must combine the N skills of the internist, the psychiatrist, and the $\omega$ physiatrist, as well as the endocrinologist and medical orthopaedist. This makes for a compleat? family physician. In the clinical investigation of the rheumatic diseases, each of these disciplines may 
as well need to be pursued. Clinical studies may have gone as far as they can in explaining the mysteries facing us. Various appendages to our major problems can still be studied, but a frontal attack can hardly be expected to be successful solely through further clinical approaches. Thus, the impetus has been towards experimentation on a more fundamental plane, and research has recently been directed towards expending our knowledge of the tissues involved, chemically, morphologically, embryologically, and in their reactions to trauma. Such investigations require not only intense and continuing training in fundamental science but also long periods of time for their completion. The time factor alone leads to difficulty by competing with the time required to become a compleat family physician. Even if we exclude interest, training, and aptitude, the time-factor allows only the very rare individual to become expert both clinically and in investigation. If the average physician is to be a competent clinician, there is just not time for him to become expert in the complexities of modern investigative procedures as well.

How can we best recruit individuals combining the two necessary types of ability at our present stage of maturity? I believe the answer lies in the teacher in the medical school with an interest in rheumatism. He must be a clinician as his area of instruction lies in clinical medicine and students rightly expect this. Since time permits only in rare instances, the perfect combination of compleat clinician and fundamental investigator, in the medical educator, clinical interest should predominate. This teacher, however, must have a critique in related fundamental problems to retain the respect of the student whose prior training has acquainted him with the basic approaches. He must make an effort to propound our problems to students using the mechanistic philosophy of disease, as the student has properly been led to expect this approach in other areas of medical education.

The importance to us of the medical educator with an interest in the rheumatic diseases cannot be over-emphasized. New blood must be infused into an organization continually if it wishes to retain its vitality, and this new blood must be good. It has to come from the young medical student whose first impressions are received from his teachers. If, because of sloppy thinking, these young ones are repelled, a field of medicine may be closed to them regardless of later attractions. The time when the student first comes to grips with a patient is a critical period of crystallization in which his future plans can be greatly affected. As Dr. Dietrich pointed out last November, the medical curriculum is full to overflowing, and the demands of the many pressure groups urging their special interests in medical education cannot be granted. I frankly admit we are one of these pressure groups; we believe that, within the limits of time and the mental capacity of the student, only a concept of our problems can be presented during the period of undergraduate instruction. The fruits of current basic research may in the foreseeable future find application in a mind prepared by a teacher of broad horizons. Above all, the student should not be repelled by loose uncritical thinking on our part; to exert influence on the highly intelligent body of undergraduate medical students, the inspiring teacher must exhibit depth as well as breadth. In graduate instruction-at the intern and resident level - we can hope to attract the individual more specifically to a given field of interest. Most forms of post-graduate medical education fail to draw individuals who may be counted upon to make significant contributions to the field. Post-graduate education does help greatly in instruction for the adequate care of patients suffering from the diseases which are our special concern, but I doubt that our knowledge will be increased by sparks struck in postgraduate education.

Being a clinician at heart, I believe that the greatest need is to continue to replenish the ranks of clinicians in the rheumatic diseases interested and disciplined in basic approaches, but I am not sure how we can attract people to work upon the fundamentals from which I am sure our answers will come. With the present emphasis on categorical grants for the study of disease, the clinician with basic orientation is in the driver's seat as the responsible investigator. My plea is for an assured method by which a continuing supply of enthusiastic, able young men may be attracted to the work of the Joint Chiefs of Staff. The burden rests on the shoulders of the teacher of undergraduate medical students. May I say that I do not mean myself, for I entered the field too early to be a compleat family physician and inspirer of young men, and have spent my declining years attending committee meetings rather than stimulating youth. The man who will lead medical students and house physicians through the intricacies of the rheumatic diseases with enthusiasm and integrity is the person to be fostered and nurtured.

If I have made my point that we need more men from this Association in the field of medical education at the undergraduate level, I should like to conclude by stating my personal opinions on how this can be achieved. The trend in medical education since the 1920s has been towards the full-time department, either strict or geographic. The 
teacher is undoubtedly more available to the student if there is a close geographic proximity. Availability is a sine qua non. The distinction between strict and geographic full-time is solely a financial one, and in most schools, strict full-time, although permitting a greater degree of availability, is seldom economically feasible. For geographic full-time, as you know, part of the income is derived from salary and part from practice. The medical schools with their sadly depleted coffers can hardly be expected to provide this salary, which will have to stem from an interested agency - either voluntary or governmental. The concept of teaching grants used in other fields by the National Institutes of Health would answer our problem of teachers and ensure their availability to students, and the attractions of the challenge of the rheumatic diseases would be carefully propounded to the young in medicine. If these ends could be attained, we could be assured that this organization would continue as an active, living force, and that patients suffering from the rheumatic diseases would be cared for with competence and understanding.

\section{Observations on the Antiphlogistic Influence of Adreno- cortical Steroids. By ThOMAs F. DOUGHerTy, Salt Lake City, Utah. (By invitation.)}

It is now recognized that ACTH, cortisone, hydrocortisone, and certain other adrenocortical steroids have the capacities to moderate the inflammatory response to a wide variety of inflaming stimuli. In our laboratory we have attempted by various techniques, which will be described, to analyse this antiphlogistic effect. It was found that a close interrelationship exists between the amount of inflaming stimulus and the amount of cortisone or other antiphlogistic hormones required to diminish the inflammatory response. It may be concluded that when the inflammatory stimulus is constant, the degree of suppression of the inflammation is directly proportional to the amount of antiphlogistic hormone given. When the intensity of the stimulus is increased within certain limits this same linear relationship holds constant. The greater the stimulus at any localized site, the greater is the amount of antiphlogistic hormone needed to suppress the inflammation, and vice versa. The experiments to be discussed indicate that not only is there a graded requirement of cortisone in inflamed tissue, but also that the hormone does not act through some general systemic mechanism, but rather exerts its antiphlogistic effect directly at the site of the inflammation.

Investigations have been made in this laboratory on the effects of hydrocortisone and $\mathrm{C}^{14}$-labelled hydrocortisone on changes in ground substance and fibroblasts as observed by electron microscopy and histochemical and radio-autographic techniques.

Role of the Adrenal Cortex in Homeostasis. By DwIGHT J. INGLE, Chicago, Ill. (By invitation.)

The secretory capacity of the adrenal cortices is very great and varies in response to changes in "need" durin different degrees of stress.

During severe stress, some of the metabolic changes resemble those caused by the administration of large amounts of cortical hormones or ACTH. It has beêf postulated that a number of the metabolic changes ass ciated with stress are due to the increased secretion cortical hormones. In some instances this seems to be true. The regression of lymphoid tissue and the redue tion in blood lymphocytes and eosinophils during stress are apparently due primarily to the increased output of hormone by the adrenal glands. On the other hand the cortical hormones may be essential for the full manf? festation of a metabolic response to stress, although $\vec{\Phi}$ change in secretory activity is not required. As example, the rise in urinary non-protein nitrogen whicbo characteristically follows a fracture is not manifest in the untreated adrenalectomized rat but does occur in simila 3 animals treated with a constant intake of adrenal cortex extract. In these experiments, an increased output of cortical hormones was not a factor in stimulatin $\vec{g}$ catabolism-adrenal cortices were absent.

Since an excess of the cortical steroids will intensif diabetes in the partially depancreatized rat, and since $\frac{P}{\mathrm{i}}$ is known that any stress causes an increased secretion of cortical hormones, it might be expected that a stres would also intensify the glycosuria of mildly diabetic rate On the contrary, the injection of toxic doses of formaldehyde into such animals caused some decrease in glycoo suria. When these experiments were repeated on adrenalectomized-depancreatized rats in which the pres adrenalectomy level of glycosuria was sustained b. constant intake of adrenal cortex extract, the admi îio tration of formaldehyde caused a still greater decrease.tie glycosuria. It was concluded that, during this stress, tho rats having intact adrenal cortices were better able ti sustain homeostasis by increasing their output of cortica steroids in response to this increased need. Whereas a similar increased output of cortical hormones in the absence of a "need" would exacerbate the diabetes, this response during stress simply prevents the corticat insufficiency that would otherwise ensue and tends te sustain homeostasis rather than to disturb it.

Growth-Hormone-Induced Osteo-Arthropathy. By C. Wके Asling, M. E. Simpson, H. D. Moon, C. H. LI, an H. M. Evans, San Francisco, Calif. (Read bog Dr. Simpson.)

Roentgenographic and histologic studies have beeß̂ made on the skeletons of fifteen intact and thirteen hypophysectomized adult female rats which receivef injections of anterior hypophyseal growth hormone. (electrophoretically homogeneous) for over a year, in dosages as high as $3 \mathrm{mg}$. daily. Control groups of fifteen intact and ten hypophysectomized rats werg injected $w$ ith serum albumin.

Joint abnormalities observed in the injected rats involved the knee, ankle, and vertebral column. Changes in the knees and ankles were almost always symmetricat and of equal severity bilaterally. Their roentgenos graphic appearance was similar to that described by 
Reinhardt and Li (1953)* in growth hormone treated adrenalectomized rats. No other joints appeared to be affected. None of the controls showed similar disorders. The deformities resulting from injections were more frequent and more severe in hypophysectomized rats.

Histological changes at the knee joint consisted of irregular articular surfaces, thickened joint linings, and excessive, irregular osteogenesis. At the ankle joint the changes consisted of excessive, irregular bony outgrowths of tibia, fibula, and calcaneus, thickened joint linings, and occasional erosion of articular cartilage. In the vertebral column, the commonest change was excessive bony growth on the ventral aspect of vertebral bodies and change in shape of intervertebral spaces.

Rate of Disappearance from Plasma of Cortisone and Hydrocortisone. By Ralph E. Peterson, Serafim L. Guerra, James B. WyngaArden, Bernard B. Brodie, and Joseph J. BunIM, Bethesda, $M d$.

Knowledge of the physiological disposition of cortisone and hydrocortisone should afford a rational basis for dosage schedule of these compounds and might lend a better understanding of the apparent merits of one steroid as compared with the other. Heretofore, no information has been available on the relative rates of disappearance of the steroids from plasma in normal subjects and in patients with disease.

Cortisone and hydrocortisone were administered intravenously to normal subjects and the rates of disappearance from plasma were determined. The analytical method employed was a modification of the method of Silber, involving extraction of steroids into methylene chloride and reaction with phenylhydrazine in sulphuric acid. The steroids were given as 100 or $200 \mathrm{mg}$. crystalline free alcohol (Merck) in $500 \mathrm{ml}$. water containing 5 per cent. dextrose and 1.5 per cent. ethanol over a 30-minute period. Counter-current distribution studies on the methylene chloride extract of plasma obtained 100 minutes after the infusion of hydrocortisone have shown that more than 90 per cent. of the steroid assayed as the phenylhydrazone is identical with hydrocortisone. The mean biologic half-life for hydrocortisone in normals was found to be 115 minutes, whereas cortisone disappeared from plasma approximately twice as rapidly, with a half-life of 65 minutes. Calculation of the volumes of distribution indicate that both steroids are distributed roughly throughout the total body water. In patients with liver disease, hydrocortisone disappears from plasma at a rate up to four times slower than normal, whereas cortisone disappears at the normal rate. It may be that the ameliorating effect of jaundice on rheumatoid arthritis is related to the slow rate of metabolic transformation of the hydrocortisone normally elaborated by the adrenal cortex. The plasma clearance rates of cortisone and hydrocortisone in patients with rheumatoid arthritis are being determined at present.

Discussion.-DR. Philip S. Hench (Rochester, Minn.): May I express my admiration for this excellent paper. Studies such as this demonstrate how the cortisones are

* Reinhardt, W. O., and Li, C. H. (1953). Science, 117, 295. metabolized by normal and by rheumatoid persons. None of these patients had jaundice. It would be most interesting to see whether the cortisones were metabolized differently by rheumatoid patients with and without intercurrent jaundice. Such a study might help to determine whether or not hydrocortisone is the antirheumatic substance $\mathrm{X}$ of jaundice.

Metabolism of Adrenal Cortical Steroids in the Synovial Cavity in Rheumatoid Arthritis. By HILDEGARD Wilson, Richard Fairbanks, Currier McEwen, and Morris ZIFF, New York City, N.Y.

The peripheral metabolism of cortisone and hydrocortisone in inflamed tissue has been investigated to gain insight into the mechanism of their anti-inflammatory activity. The following evidence for the local transformation of injected corticosteroid by rheumatoid synovial tissue has been obtained. Chromatographic analysis of post-injection synovial fluid showed substantial amounts of a number of metabolites of intraarticularly injected cortisone and hydrocortisone. Only trace amounts were found when the uninjected contralateral knee was aspirated at the same time, indicating local metabolism, since if metabolites had been formed elsewhere they would have returned in more nearly equivalent concentrations to each side.

Both steroids yielded products of greater and lesser mobility, indicating that the tissue was capable of effecting a variety of metabolic transformations. A different pattern of metabolism was found for each steroid. Cortisone (locally inactive) yielded hydrocortisone, several other corticosteroids, and an abundant noncorticosteroid component. Hydrocortisone (anti-inflammatory in the joint) gave rise to at least three other corticosteroids, $11 \beta$-hydroxy- $\Delta^{4}$-androstene-3, 17-dione, and another 17-ketosteroid. The difference in metabolic pattern, together with the presence of relatively large amounts of hydrocortisone after cortisone injection, raises the question whether the unique anti-inflammatory effect of hydrocortisone in the synovial cavity lies in its transformation into a specific metabolic product.

Discussion.-DR. Joseph L. Hollander (Philadelphia, $P a$.): I should like to congratulate Dr. Wilson and her colleagues on their wonderful paper. The experimental data and the conception of the experiments are very good.

We have been using a slightly different approach in trying to find out how hydrocortisone works in the joint. Our work ties in very closely with the work of Dr. Dougherty which you heard earlier.

We find no disagreement with Dr. Wilson's results and wish only to commend them. Our only slight difference is in how some of the results are interpreted.

First of all, mention is made of conversion of cortisone to hydrocortisone in the joint. We found that also. Of our 26 cases, however, we found it in only one, in a patient who also got 24-hour clinical relief in the inflamed joint from an injection of cortisone. As you know, this happens in only a small percentage. I wonder if some people are able to convert cortisone to hydrocortisone in their tissues, and others not.

Our difference in approach might be likened to the difference between trying to find out what a family eats by looking in the refrigerator or by looking in the garbage can. In other words, if we try to discover where the injected material is stored and what it is like when 
stored, we may, perhaps, reach one conclusion indirectly. If we "look in the garbage can" at what is not absorbed from this synovial fluid, we may infer the "diet" of the synovial tissue from that also.

Much of the injected hydrocortisone acetate or any other esters we have tested, is absorbed by the synovial fibroblasts, or at least into the synovial lining. We have not proved, as Dougherty has, that hydrocortisone goes into the fibroblasts, but we certainly agree. By taking synovial biopsies at various intervals after injection, we have shown that the hydrocortisone is stored in the synovium as the ester: in other words, the ester is not split off.

Therefore, we have assumed that, at least in storage before the hydrocortisone is actually used, it exists as the ester. We differ in the way we interpret these changes. We do not feel that the metabolite of hydrocortisone is necessarily the active agent, but that hydrocortisone itself may still be the active agent.

Dr. Edward W. Boland (Los Angeles, Calif.): The data presented in the last two papers are highly significant. It may be hoped that through investigation of this type the reasons for differences in potency between the glycogenic adrenal cortical steroids, as well as their various esterified preparations, will be clarified. Indeed, the assayists are to be complimented.

From comparisons of clinical responses to oral administration, we are convinced that hydrocortisone (free alcohol), cortisone (free alcohol), hydrocortisone acetate, and cortisone acetate exhibit definite differences in antirheumatic potency. Differences in solubility of the compounds, or of the relative weights of the active principle in the case of esters, do not fully explain the divergencies. The data presented may imply that variances in rates and modes of metabolism and in survival times following absorption are also important.

To complicate the issue further, it may be appropriate at this time to relate some very preliminary observations which Dr. Headley and I have made with one of the halogenated derivatives of hydrocortisone, 9-alphafluoro hydrocortisone acetate.* To date we have administered this preparation for brief periods of days to only three patients - each with rheumatoid arthritis. No conclusions can be drawn from these pilot trials, but, to us, some of the observations are very interesting.

In animals, 9-alpha-fluoro hydrocortisone has high glycogenic activity and displays strong sodium-retaining properties. Acute toxicity studies have shown that it is not lethal to mice in dosages up to $1,000 \mathrm{mg} . / \mathrm{kg}$. Dr. George Thorn and his group have found the derivative extremely effective in maintaining patients with Addison's disease; as sole treatment, dosages of 0.25 to $0.5 \mathrm{mg}$. 9-alpha-fluoro hydrocortisone per day have been sufficient. Based on electrolyte studies, suppression of 17-ketosteroid excretion, and eosinopenic response, it is my understanding that Dr. Thorn has estimated that the compound is at least 25 times as potent, by weight, as cortisone, and that its efficiency in Addison's disease is comparable with that of aldosterone (electrocortin).

In the three patients to whom we administered 9-alphafluoro hydrocortisone acetate, rheumatoid activity was graded as severe, moderately severe, and moderate, respectively. The drug was given orally in divided doses of $1 \mathrm{mg}$. each, the initial total daily dosage being $4 \mathrm{mg}$. in one patient and $6 \mathrm{mg}$. in the other two. These small doses were prompted by Dr. Thorn's observations and animal studies which suggested a high degree of potency.

* See page 291 for full article.
The patients had received no recent treatment of significance beforehand and no auxiliary measures were $\overline{3}$ employed except salt-poor diets.

Improvement in the articular manifestations began $\frac{}{\omega}$. within 6 hours of the first dose (total $2 \mathrm{mg}$.) in two patients, and within 17 hours (total $3 \mathrm{mg}$.) in the other. The patient with severe disease had been confined to bed, unable to feed herself, or to reach for the telephone. She was able to sit in a chair after 2 days, to walk to the bath- $\frac{\bar{T}}{\bar{n}}$ room after 4 days, and to walk about the room without $\frac{\bar{\sigma}}{\partial}$ pain on the sixth day. The erythrocyte sedimentation $\mathbb{\Phi}$ rate (Westergren) dropped progressively in 8 days from 96 to $29 \mathrm{~mm}$./hr. Similar, though less dramatic, improvement was seen in the other two patients and the response $\overrightarrow{0}$ seemed to compare favourably with that noted from the ? much larger suppressive doses required with hydro- $\overrightarrow{\vec{\omega}}$ cortisone and cortisone.

We have no data regarding adverse reactions. So far there have been none, but from available data regarding the compound's physiologic activity, they should be $\vec{\omega}$ anticipated, particularly salt-and-water retention.

9-alpha-fluoro hydrocortisone acetate seems to possess $\rightarrow$ striking antirheumatic activity and that its potency per milligram may be many times that of hydrocortisone and $\vec{A}$ cortisone. If further investigations bear out this impres- 음 sion, a greater impetus may be provided for trials of other $\overrightarrow{ }$ analogues or derivatives of hydrocortisone, in the hope $\vec{\square}$ that one with wide dissociation between anti-inflam- $\mathbb{D}$

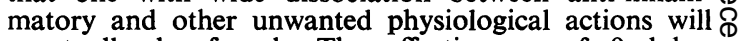
eventually be found. The effectiveness of 9-alpha- 3 fluoro hydrocortisone in such small doses would imply that certain properties of hydrocortisone can be changed by a relatively minor modification of its chemicgl $\vec{c}$ structure.

Dr. Theodore B. Bayles (Boston, Mass.): As usuînl the patients in Boston seem more resistant to cortisone and its analogues. In collaboration with Dr. George W. Thorn's group, we have treated two patients with active $\bar{\partial}$ rheumatoid arthritis with fluoro hydrocortisone provided by Squibb and Company. When we gave a single 5-mg. dose by mouth, there was very little antirheumatic $\varrho$ effect apart from a slight drop in the sedimentation rate. $\overrightarrow{\vec{\sigma}}$ The response to $5 \mathrm{mg}$. twice a day orally seemed equi- $\frac{0}{3}$ valent in antirheumatic effect to $75-100 \mathrm{mg}$. a day of $\frac{\supset}{\supset}$ cortisone. The patients were maintained in the Robert Breck Brigham Hospital on a rigid, low sodium diet? of $1 \mathrm{~g}$. or less, and $3 \mathrm{~g}$. potassium chloride daily. Fluids were unlimited. One patient was a 62 -year-old woman with auricular fibrillation and arteriosclerotic heart disease, and the other a young man aged 19 years. 3 Up to the present time on the 5-mg. twice a day dosage, neither patient has shown fluid retention or other mineralocorticoid effects of an unpleasant nature. $₹$ Certainly such limited experience allows no significant 을 conclusions at the present time, except that this analogue is probably 7 to 10 times as effective antiphlogistically $\frac{D}{0}$ as cortisone.

DR. JoSEPH J. Bunim (Bethesda, Md): I did not include $\bar{N}$ some data in my paper because of time, but, in view of Dr. Boland's and Dr. Bayles's remarks it may be perti- $N$ nent. We administered orally to normal subjects $300 \mathrm{mg}$. N hydrocortisone (free alcohol); in a second experiment, $\omega$ $300 \mathrm{mg}$. cortisone (free alcohol); in a third, $300 \mathrm{mg}$. cortisone acetate; in a fourth, hydrocortisone acetate.

It is interesting to see what the peak concentration in $\frac{C}{\Phi}$ the blood was at the end of 8 to 12 hours. The time interval varied from one experiment to another. Hydro-? cortisone (free alcohol) reached a peak level of thirty

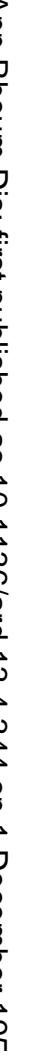

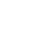


times the normal concentration in the blood $(300 \mu \mathrm{g}$. as against the normal $10 \mu \mathrm{g}$.).

The same dose of cortisone (free alcohol) given by mouth caused a peak concentration of $200 \mu \mathrm{g}$. per cent., the same dose of cortisone acetate reached a peak of ten times the normal, $100 \mu \mathrm{g}$. per cent. The same dose of hydrocortisone acetate made practically no impression at all on blood concentration.

We have also studied antirheumatic and certain metabolic effects of fluorohydrocortisone in one patient. This was a white female patient aged 52, with rheumatoid arthritis of 25 years' duration, whose cortisone needs were well-known. She was allowed to have a flare of her arthritis by lowering the dose of cortisone from 75 to $50 \mathrm{mg}$. per day. She was then given $1 \mathrm{mg}$. fluorohydrocortisone per day in addition to the $50 \mathrm{mg}$. cortisone. No improvement resulted and the dose of fluorohydrocortisone was increased to $5 \mathrm{mg}$. per day. She then had a definite, but incomplete, response, and became about as well as she had been on the $75 \mathrm{mg}$. cortisone alone, in that she had less pain and less tenderness and slightly less swelling of her joints than she had at the beginning of this study. Then the cortisone was tapered and discontinued completely, but the fluorohydrocortisone was continued at $5 \mathrm{mg}$. per day. With this change in therapy, the patient had a marked increase in her symptoms and became worse than she had been on $75 \mathrm{mg}$. cortisone alone. During this time she was on a constant fluid, caloric, and sodium intake, consisting of $2 \mathrm{~g}$. sodium per day. The urinary sodium showed an abrupt fall when the fluorohydrocortisone was started, the haematocrit fell from 37.5 to $31 \cdot 5$, her weight rose from 71.8 to $75.7 \mathrm{~kg}$. in 14 days of therapy, and she developed massive oedema of her extremities. In this study no definite antirheumatic effect of fluorohydrocortisone alone was demonstrated, but it was found that combined fluorohydrocortisone and cortisone had an enhanced antirheumatic effect; $5 \mathrm{mg}$. fluorohydrocortisone seeming to be equivalent to about $25 \mathrm{mg}$. cortisone. A marked sodium-retaining effect of the drug was demonstrated.

DR. WILson: We are aware of Dr. Hollander's very interesting experiments. Our studies differed in that we used cortisone and hydrocortisone free alcohols, rather than the acetates. We agree that all patients probably do not convert cortisone to hydrocortisone. In our previous report* one patient appeared to have converted cortisone acetate to tetrahydrocortisone.

It is certainly important for us to know more about the chemical interrelationships between the steroid hormones injected intra-articularly, and the compounds taken into the living tissue and the blood. This is obviously a complex subject. For one thing, the type of metabolite one finds depends on the time interval after injection at which fluid is withdrawn and analysed. We found quite a different pattern 3 hours after hydrocortisone from that seen after 30 minutes.

Another word of caution might be interposed regarding the difficulty of actually identifying a corticosteroid compound. Parallel mobility on paper chromatograms, even when there are other similarities to a known substance, do not necessarily prove the identity of an unknown. We have seen that cortisone and hydrocortisone are rapidly transformed in the synovial cavity, and that some of the products may retain certain properties of the original hormone. So it seems that a good deal of work lies ahead of us before we can define the nature and amounts of the steroids present at any one time, or relate

* Proc. Soc. exp. Biol., 83, 648 (1953).

our findings to the mechanisms of their anti-inflammatory effects.

\section{Interim Report of the American Rheumatism Association's Committee for the Cooperative Study of Cortisone Therapy in Rheumatoid Arthritis}

Presented by

\section{Dr. Currier McEwen}

\section{Chairman of the Committee}

This is the second report of this study involving the cooperative effort of 25 clinics in the United States and Canada and made possible by a grant from the Arthritis and Rheumatism Foundation. It is emphasized that this is not a "forward moving" study, but an analysis of clinic records of the judgment of physicians as to the effect of cortisone administration in individual patients. These effects are not compared with those induced by any other agent.

Records of 546 patients with rheumatoid arthritis have been analysed (63 per cent. females, 37 per cent. males). At the start of cortisone therapy, 25 per cent. had had the disease less than 3 years, 50 per cent. less than 7 years, and 75 per cent. less than 12 years. At the end of the 3-year period of study 432 (79 per cent.) were still under observation, 85 (15 per cent.) had left the study, and 29 ( 5 per cent.) had died. Of the 432 patients still under observation, 252 (58 per cent.) were still receiving cortisone, in 65 (15 per cent.) cortisone had been stopped because of a remission, in 102 (23 per cent.) cortisone had been stopped because of an untoward effect, and in ten ( 2 per cent.) for other reasons.

The results in 546 patients followed for 12 months and in $\mathbf{3 1 0}$ patients followed for $\mathbf{3 6}$ months are summarized in Tables I and II (overleaf). In these Tables the grade of improvement and functional capacity are shown according to the criteria adopted by the American Rheumatism Association.*

In 159 patients with rheumatoid subcutaneous nodules, the nodules increased in size, number, or both in 21 , remained unchanged in 79 , decreased in 37 , and disappeared in nine. There was no record in thirteen.

In 43 per cent. of patients the daily dose of cortisone after the first 3 months of treatment averaged not more than $50 \mathrm{mg}$., while in 57 per cent. it averaged more than $50 \mathrm{mg}$. As would be expected, there were many more remissions in the patients who required smaller doses than among those who required larger doses. Conversely, undesired effects occurred somewhat more frequently in those receiving the larger doses.

One or more undesired effects which were considered to be of major significance (psychosis, peptic ulcer, fluid retention, pathological fracture, glycosuria, thrombosis, infection or masking of infection) occurred in 46 per cent. of the patients. Minor undesired effects (moonface, acne, hirsutism, striae, emotional instability, redistribution of fat, menstrual irregularity, excess fatigability)

* Steinbrocker and others (1949). J. Amer. med. Ass., 140, 659. 
TABLE I

546 PATIENTS OBSERVED FOR A PERIOD OF 12 MONTHS

\begin{tabular}{|c|c|c|c|c|c|c|c|c|c|c|c|c|c|c|c|}
\hline \multirow{3}{*}{$\begin{array}{l}\text { Months since } \\
\text { Start of } \\
\text { Cortisone }\end{array}$} & \multicolumn{10}{|c|}{$\begin{array}{c}\text { Progress of } 408 \text { Patients on Cortisone } \\
\text { for } 12 \text { Months }\end{array}$} & \multicolumn{5}{|c|}{$\begin{array}{l}\text { Disposition of } 138 \text { Patients on Cortisone } \\
\text { for less than } 12 \text { Months }\end{array}$} \\
\hline & \multicolumn{5}{|c|}{ Grade of Response } & \multicolumn{5}{|c|}{ Functional Class } & \multicolumn{4}{|c|}{ Reasons for Stopping Cortisone } & \multirow{2}{*}{$\begin{array}{c}\text { Left Study } \\
\text { or Died } \\
\text { while on } \\
\text { Cortisone }\end{array}$} \\
\hline & I & II & III & IV & N.R. & I & II & III & IV & N.R. & Remission & $\begin{array}{c}\text { Insufficient } \\
\text { Benefit } \\
\text { or Worse }\end{array}$ & Toxicity & Other & \\
\hline 0 & - & - & - & - & - & 23 & 133 & 209 & 51 & 2 & - & - & - & 一 & 一 \\
\hline 6 & 15 & 167 & 179 & 38 & 9 & 50 & 217 & 113 & 20 & 8 & 16 & 31 & 25 & 1 & 2 \\
\hline 9 & 22 & 157 & 181 & 40 & 8 & 59 & 222 & 101 & 20 & 6 & 33 & 37 & 33 & 2 & 4 \\
\hline 12 & 22 & 151 & 191 & 39 & 5 & 59 & 216 & 114 & 16 & 3 & 43 & 47 & 41 & 3 & 4 \\
\hline
\end{tabular}

TABLE II

310 PATIENTS OBSERVED FOR A PERIOD OF 36 MONTHS

\begin{tabular}{|c|c|c|c|c|c|c|c|c|c|c|c|c|c|c|c|}
\hline \multirow{3}{*}{$\begin{array}{c}\text { Months since } \\
\text { Start of } \\
\text { Cortisone }\end{array}$} & \multicolumn{10}{|c|}{$\begin{array}{c}\text { Progress of } 26 \text { Patients on Cortisone } \\
\text { for } 36 \text { Months }\end{array}$} & \multicolumn{5}{|c|}{$\begin{array}{l}\text { Disposition of } 284 \text { Patients on Cortisone } \\
\text { for less than } 36 \text { Months }\end{array}$} \\
\hline & \multicolumn{5}{|c|}{ Grade of Response } & \multicolumn{5}{|c|}{ Functional Class } & \multicolumn{4}{|c|}{ Reasons for Stopping Cortisone } & \multirow{2}{*}{$\begin{array}{c}\text { Left Study } \\
\text { or Died } \\
\text { while on } \\
\text { Cortisone }\end{array}$} \\
\hline & 1 & II & III & IV & N.R. & 1 & II & III & IV & N.R. & Remission & $\begin{array}{l}\text { Insufficient } \\
\text { Benefit } \\
\text { or Worse }\end{array}$ & Toxicity & Other & \\
\hline 0 & - & - & - & - & - & 1 & 5 & 12 & 8 & - & - & - & - & - & - \\
\hline 6 & - & 10 & 14 & 2 & - & 2 & 12 & 8 & 4 & - & 16 & 31 & 25 & 1 & 2 \\
\hline 9 & 1 & 7 & 14 & 3 & 1 & 3 & 11 & 8 & 4 & - & 33 & 37 & 33 & 2 & 4 \\
\hline 12 & 1 & 9 & 13 & 2 & 1 & 2 & 12 & 9 & 3 & - & 43 & 47 & 41 & 3 & 4 \\
\hline 24 & 1 & 10 & 13 & 1 & 1 & 4 & 12 & 7 & 2 & 1 & 70 & 85 & 71 & 15 & 16 \\
\hline 36 & 1 & 9 & 14 & 2 & - & 4 & 12 & 8 & 2 & - & 77 & 99 & 77 & 15 & 16 \\
\hline
\end{tabular}

were reported in 72 per cent. of the patients. There appeared to be a greater tendency for pathological fractures and infections to occur in the older patients.

Twenty-nine of the patients died during the course of the study, of whom 23 were over 50 years of age and thirteen were over 60 . In 23 (4 per cent.) of the 546 patients, the cause of death was possibly related to cortisone therapy.

Discussion.-Dr. Lewis Cozen (Los Angeles, Calif.): I did not understand the percentage of major toxic effects in the entire group. I should like to ask Dr. McEwen to elucidate that.

DR. MCEWEN: In the total group of 546 patients 54 per cent. had no major undesirable effects, or, conversely, 46 per cent. did have them.

Dr. Russell L. Cecil (New York, N. Y.): Dr. McEwen, I wonder if you had the same reaction we had on analysing our figures. When we got down to statistics, we concluded that unfortunate reactions to cortisone therapy were not too frequent. We found, in other words, that we were doing a better job for our patients with cortisone than we had thought we were doing. I wonder if others have had the same feeling.

I think there is a psychological explanation; when you do get into trouble, when a patient has a severe emotional reaction, or an ulcer starts bleeding, you begin to think, "I don't want to fool with this stuff".

Then you study forty or fifty cases and see some of the good results obtained, and you feel better.
Dr. Charles M. Plotz (Brooklyn, N.Y.): Two years ago we presented a comparison between one hundred patients who had been treated with cortisone and a group

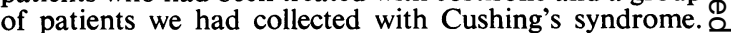
I think it is interesting to notice that Dr. McEwen's $\overrightarrow{\vec{S}}$ statistics to-day are very similar to those which we had at $\frac{0}{3}$ that time.

I should like to ask Dr. McEwen why he includes glycosuria as a major undesirable side effect, and, also, how he explains the fact that, while the total incidence of side-reactions is approximately the same in the older age group as in the other patients, the incidence of infection seems considerably higher in the older patients.

Of course the incidence of pathological fracture is higher among the older patients because of the normalo incidence of osteoporosis in older people.

Dr. J. Albert Key (St. Louis, Mo.): Has there been 을 any attempt to determine whether or not this therapy has influenced the natural course of the disease.

Dr. David H. Kling (Los Angeles, Calif.): Was cortisone the only treatment, especially in the cases whicho received the smaller dosage, or were salicylates or other $N$ adjuvants given?

DR. MCEwEN: It is always disconcerting, to see how $\omega$ statistical analyses of large numbers of patients can upset one's ideas regarding therapeutic effects.

For example, I should have sworn that the subcutaneous nodule of rheumatoid arthritis melts aways under cortisone; I certainly gained that impression from ${ }^{-}$ seeing what has happened in a few patients. But here, $T$ 
in the analysis of a large number of nodules, we find many that were not affected.

In answer to Dr. Plotz, I have no good reason why glycosuria was included as a major side-effect. I think he is implying that we should not worry too much about it, and with that idea I agree entirely. I would rather not try to explain the question of infections in the older patients until the data have been more carefully appraised by statistical standards; it may well be that the differences are not statistically valid.

So far as Dr. Key's question is concerned, Dr. Bunim is to present a paper immediately after this report in which an attempt is made to draw conclusions regarding the natural course of the disease. I think his data will answer Dr. Key's question better than mine.

In answer to Dr. Kling, may I say that we have data on the point he has raised. For instance, as I remember it, 71 per cent. of the patients receiving cortisone also received salicylate. We have data on the clinic physician's opinion as to the usefulness of various forms of concomitant therapy, but so far we have not fully analysed them.

A Comparison of Cortisone Acetate and Aspirin in the Treatment of Early Cases of Rheumatoid Arthritis. By H. F. West, * Sheffield, England (by invitation).

At the 1953 meeting in New York, Prof. A. Bradford Hill and Prof. J. H. Kellgren described in detail the nature of the strictly controlled cortisone acetate and aspirin trial in the treatment of early cases of rheumatoid arthritis which had been organized by a committee of the Medical Research Council and Nuffield Foundation. In this study 61 patients in the early stages of rheumatoid arthritis were allocated at random to treatment with either cortisone acetate ( 30 cases) or aspirin ( 31 cases). Two comparable groups of these cases were thus assembled and they have now been treated and observed for one year. For most of the year treatment was "individualized" by the physician-in-charge of each patient at a level sufficient to restore maximal functional efficiency without producing serious side-effects.

Observations made one week, 8 weeks, 13 weeks, and approximately one year after the start of treatment reveal that the two groups have run a closely parallel course in nearly all the recorded characteristics, viz. joint tenderness, range of movement of wrist, strength of grip, tests of dexterity of hand and foot, and clinical judgments of the activity of the disease, of the progress of the patients, and of their functional capacity. The haemoglobin level and blood sedimentation rate were slightly more favourably influenced by cortisone acetate, but in no other respect do the two groups differ materially.

In each group the disease was judged at the end of one year to be slightly active or inactive in about threequarters of the patients, and in each group some twofifths of the patients were regarded as capable of normal work and activity. For practical purposes, therefore, there appears to have been surprisingly little to choose between cortisone and aspirin in the management of these early cases of rheumatoid arthritis.

* Dr. West spoke as a representative of the Joint Committee of the British Medical Research Council and Nuffield Foundation which organized the Cortisone-Aspirin Trial.
Discussion.-Dr. CuRrier McEwen (New York, N. Y.): At the time the evaluations were made was therapy continued or did you stop therapy temporarily?

Dr. William H. Goodson, JR. (Kansas City, Mo.): Did the patients on cortisone have thyroid or any other endocrine preparation?

Dr. Ephraim P. Engleman (San Francisco, Calif.): First, do we have any information regarding the severity of the disease in these two groups? Secondly, did the examiner know what drug was being used?

Most of the criteria used here are subjective, with the exception of the haemoglobin and sedimentation rate, and, specifically, no information is given regarding the effect upon effusion.

Dr. Russell L. Cecil (New York, N.Y.): Were there any toxic effects in the adults on aspirin?

Dr. David H. Kling (Los Angeles, Calif.): What was the dosage of cortisone and was it a constant dose or was it on a decreasing scale? What was the dose of salicylate? Evidently it took cortisone to make us realize how good a drug aspirin is.

Dr. Lewis Cozen (Los Angeles, Calif.): Was the total series large enough to be significant, statistically?

Dr. J. Albert Key (St. Louis, Mo.): Was any cognizance taken as to how these patients felt? I think that is a very important asset on the side of cortisone. It seems to me that if you give patients cortisone they feel a lot better. After all, that is what they come to the doctor for.

Dr. John Lansbury (Philadelphia, Pa.): Were there any side-effects from cortisone?

Dr. Charles M. Plotz (New York, N.Y.): I think, in connexion with what Dr. Key said, I should like to know how the dose of cortisone was regulated in these patients. Was it regulated to keep them at the same level of subjective or objective improvement as aspirin would give, or was the dose of cortisone given for maximum improvement?

DR. WEST: We made observations quite frequently throughout this trial; those recorded on the chart were taken when the patients were having their maintenance dose. They were not taken when the patients were off treatment except in those few who were considered not to need further treatment.

In answer to the question whether they were given any thyroid in addition to cortisone, none of them were given thyroid or other endocrine therapy.

Do we have any data as to severity? I think the best data regarding severity is the sedimentation rate and the scatter of sedimentation rates. The average was $42 \mathrm{~mm}$./hr (Wintrobe) for both groups when treatment was begun.

Toxic effects? An equal number of side-effects was seen with both cortisone and aspirin. None of these was severe, and in no case was treatment stopped because of them. In some cases it was reduced slightly. There were no fatalities or serious side-effects at all.

Dosage of cortisone? The cortisone was given on a 3-monthly plan. At the beginning of the 3 months they started with the originally suggested schedule of high dosage, dropping down after 4 or 5 days to $100 \mathrm{mg}$., and that was kept on for a week. The dose was then dropped to $50 \mathrm{mg}$. for one week. After that, for the rest of the 3 months, the physician would give as much as was considered necessary short of causing severe side-effects. 
At the end of 3 months, treatment was stopped for one week, and a record was made during that one week, which is not included in the chart.

Was the series large enough? I think the statisticians thought the series was large enough.

What about the feelings of the patients? In the early weeks of treatment the cortisone patients knew they were on cortisone, but towards the end of the year they disputed which tablet was which, indicating that the feelings of well-being had evaporated somewhat.

Results of Prolonged Cortisone Administration in Rheumatoid Arthritis-A Four-Year Study. By JOSEPH J. Bunim, Bethesda, Md., and Morris ZifF and Currier McEWEN, New York, N.Y.

The purpose of this report is to present the data collected from observation over a 4-year period of 78 patients with rheumatoid arthritis (including nine cases of juvenile rheumatoid arthritis) who were treated with cortisone for intervals varying from a few weeks to almost 4 years. The patients were examined every 4 weeks, or more often, during the study. At the end of the period 44 per cent. of the patients who had remained under observation were still receiving cortisone daily. The results have been analysed to yield information concerning the following:

Composition of the group according to certain clinical features of rheumatoid arthritis;

Age and sex distribution;

Duration and stage of arthritis;

Duration of cortisone therapy;

Average daily maintenance dose;

Results in functional improvement as measured by four different criteria;

Relation of duration of therapy to grade of therapeutic response;

Comparison of certain factors in the groups that exhibited Grade I and Grade III or IV response;

Behaviour of subcutaneous nodules during therapy;

Appearance or extension of bone destruction despite maintenance therapy and good clinical response;

Undesirable effects, peptic ulcers, fractures, and one death from overwhelming sepsis.

Discussion.-Dr. Arthur W. Bagnall (Vancouver, B.C., Canada): I wonder whether remission was achieved while still on the drug or after it was stopped. What was the period of time involved?

DR. H. F. WeSt (Sheffield, England): I should like to ask whether Dr. Bunim saw in any patient with rheumatoid arthritis a marked improvement in the radiological appearance of any joint during the course of one year. I ask because I have not seen this occur, but I have seen a patient with ankylosing spondylitis, with hand involvement, improve remarkably radiologically on high ACTH therapy.

Dr. Philip S. Hench (Rochester, Minn.): This is a thought-provoking paper. There is more to it than meets the eye. Some of Dr. Bunim's patients under cortisone therapy have presented an interesting clinical dissociation: even though they are subjectively and objectively better, certain laboratory data suggest progression of the disease, e.g. a "roentgenographic worsening". All of us have seen such clinical dissociations in patients who have developed either a spontaneous clinical remission or a therapeutic one induced by older $\stackrel{\vec{D}}{\mathbb{D}}$ remedies. I have often seen a rheumatoid spondylitic $\frac{5}{3}$ develop what seems to be a complete clinical remission which continued for several years; but as time went on, $\underline{\square}$. despite the continued remission, the changes in the spinal roentgenograms became much more advanced.

Whenever I see such a dissociation I ask myself: $\stackrel{\oplus}{+}$ Which is the best index of the activity of disease, the symptomatic remission or the roentgenographic (or other)흐 "evidence" of progression? Which is the "disease", the $\overline{\bar{\omega}}$ disturbed physiology which produces the symptoms or $\vec{\nabla}$ the local pathological change which produces radio- $\_$ logical abnormalities? Certainly, as far as the patient is concerned, it is the former. Perhaps the "progressive" $x$-ray changes" are manifestations, not of progressively $\overrightarrow{0}$ active disease in spinal tissues, but of progressive healing, $\rightarrow$ the increasing syndesmophytes representing a specialized $\vec{\omega}$ form of scar tissue, the slow formation of which continues long after active inflammation has subsided.

During the last 6 years we have all run into certain? difficulties related chiefly to semantics. First, the results $\vec{\omega}$ of the cortisones were so unlike that of older remedies $A$ that we had to establish new criteria to indicate the speed $\omega$ and degree of relief. I note that our Association now $\vec{A}$ has a new committee to bring our therapeutic criteria 0 up to date.

In evaluating the significance of a dissociation such as we are now discussing, we must ask ourselves: Is the patient worse or is the "chart" worse? I think it is quite possible for a patient to be truly better and his disease $\frac{\mathbb{D}}{3}$ really less active, although some one biological alteration $\bar{\sigma}$ may appear worse. Rheumatoid arthritis presents many such dissociations: marked clinical improvement with $\overrightarrow{\vec{\theta}}$ tardy normalization of serum globulin, sedimentation $\vec{\sigma}$ rate, etc.

This leads to the question: "Just what is the diseage known as rheumatoid arthritis and where is its mano headquarters?" Sometimes it is chiefly a disease of joints, but often the systemic manifestations are more $\bar{\partial}$ disturbing than the articular. Which organ is the site of this major disturbance, the primary pathological $\frac{\mathrm{Q}}{\mathbb{Q}}$ physiology? Which organ controls the fate of the rheumatoid joint? Is it the liver, the adrenals, the $\overrightarrow{\vec{\sigma}}$ synovia? After 30 years in rheumatology, I must 3 confess I do not know.

DR. Bunim: I don't think Dr. Hench expects ano answer! In reply to the first question on remissions, however, we at first had some doubts about what we should call a remission. A patient on cortisone, having complete relief of all symptoms, a complete suppression, $\frac{\sigma}{3}$ can one say he has remission? We thought back to our:friends the haematologists, who talk about the patient $\overline{ }$ with pernicious anaemia who has remission and will 3 continue to have a remission so long as he gets livero extract or $\mathbf{B}_{12}$.

However, this quandary was not as great as we expect- $D$ ed. Of the seventeen patients who had remission, only음 one was continued on the drug. In sixteen patients the drug was discontinued, and not one of them has yet had $N$ a relapse, though some have now been off it for 3 years.

In answer to Dr. West's question, we have not yet $\mathrm{N}$ encountered a single case of marked improvement on $x$ ray as a result of, or during, cortisone therapy.

Metabolic Effects of Long-Term Cortisone Therapy. By을 Evan Calkins, Donald M. Mitchell, and Walter BAuEr, Boston, Mass.

The use of maintenance cortisone in many patients with $\square$ 
rheumatoid arthritis has introduced new physiological problems to medical practice. Although the initial metabolic effects of cortisone have been defined; the extent to which these effects are modified with prolonged therapy is not fully understood.

Two patients with chronic, active, rheumatoid arthritis were therefore studied with electrolyte and nitrogen balances before and immediately after the initiation of maintenance cortisone, and at intervals during a subsequent period of 2 and 4 years, respectively. The effect of alterations in calcium and potassium content of the diet and of testosterone was observed. The pattern of one patient's response to stress was studied on two occasions by determining the metabolic balances, eosinophil counts, and 17-keto- and formaldehydogenicsteroid excretion before and after elective surgical operations, carried out under constant diet and cortisone dosage. These results were compared with the response to sudden increase in and cessation of cortisone and to ACTH administration.

Results show that in these patients, who were initially in negative nitrogen balance, prolonged administration of cortisone was associated with an increased and continued loss of nitrogen and other body constituents. Sudden increase in cortisone and surgery were primarily manifested by sodium retention, rather than by an added acute catabolic response. Although there was apparently no adrenal cortical response to surgery, evidence suggests that there may have been increased "utilization" or altered metabolism of adrenal steroids.

Punch Biopsy of Synovial Membrane in the Diagnosis of Articular Disease. By Howard F. Polley, William H. Bickel (by invitation), and Malcolm B. DocKERTY (by invitation), Rochester, Minn.

Punch biopsy of synovial membrane now has been carried out 335 times on 276 patients. Minor improvements in the instrument and in the technique of its use (reported in 1951) have added to the facility of this procedure. Punch biopsy of synovial membrane may now be performed on ambulatory as well as hospitalized patients. Transient symptomatic haemarthrosis has been the only cause of morbidity; this has occurred after only four biopsies (about 1 per cent.).

The knee is at present the most suitable site for punch biopsy of synovial membrane, but in certain instances the ankle, elbow, and shoulder joints have been successfully examined by this procedure. Synovial membrane so obtained has been satisfactorily comparable to that obtained by arthrotomy or other surgical procedures. Trials of a new, smaller instrument, which may be suitable for biopsy of small joints, such as the interphalangeal joints, is now in progress.

Punch biopsy is especially helpful in the diagnosis of monarthritis. Recognition of rheumatoid arthritis, gouty arthritis, articular infections, metaplasia of synovial membrane, and other articular diseases has been accomplished. Punch biopsy also provides the opportunity for additional information in the evaluation of therapy and study of the serial changes in synovial membrane both in various rheumatic diseases and in others in which synovitis may be an associated finding. With this procedure suitable material also may be obtained for tissue culture and chemical studies. As additional experience is accumulated, concepts of the pathogenesis of articular diseases may be clarified.

Discussion.-DR. Philip S. Hench (Rochester, Minn.): Perhaps it is not immodest to say that in about 98 per cent. of cases of articular disease an experienced rheumatologist should be able to make a satisfactory clinical diagnosis from the history, physical examination, roentgenograms, and routine laboratory tests. But in about 2 per cent. of our cases we need special techniques such as that described by Dr. Polley.

In India all cows are sacred. In the United States, until recently, the human joint, even when diseased, was a "sacred cow", not to be violated even by the pathologist doing an autopsy on a dead rheumatoid patient! When I was a young rheumatologist at the Mayo Clinic we had a very able and zealous pathologist who prided himself on the high percentage of post mortems obtained and on the completeness of the examinations. When relatives refused to permit him to extend an abdominal (operative) incision made before death he was still able to make an extensive examination, not perhaps extending to the pineal but certainly including the thyroid. And yet so inviolate were the joints in those days that he would examine a diseased one for us only on the rarest occasions, a most frustrating experience for me.

In recent years the situation has improved somewhat as far as joints at post mortem are concerned. But incisional biopsies of joints are still performed on rheumatic patients with undue hesitation, and muscle biopsies are done even less often. How little we know about the pathological histology of articular tissue in lupus erythematosus, in psoriasis! And how very fragmentary is our knowledge of diseased muscles! I develop influenza and my muscles ache all over: what type of inflammation is present? What changes characterize the muscles in an "acute wry neck"? And when my derrière hurts after a spring horse-back ride, are the symptoms due to some temporary inflammation in the muscles or a non-inflammatory chemical change?

But now we can extend our knowledge of synovial pathology, at least of the knees, without the necessity for incisional biopsies, scars, etc., and Dr. Polley's needle biopsies have been very useful in diagnosis.

Dr. J. Albert Key (St. Louis, Mo.): I was not too impressed by the title of this paper because it called to mind immediately a paper by Mark Sherman, which very few people have ever seen, on the non-specific inflammatory changes in synovial tissue. Often we have trouble making diagnoses after surgical biopsy.

In a biopsy of tumours, a good deal depends upon where you take the tissue, and the same is true in biopsy of synovial membrane.

However, after having seen Dr. Polley's slides and his ingenious instrument, my opinion has changed.

Dr. Currier McEwen (New York, N.Y.): We have been rather discouraged with the results we have obtained to date with this technique, because of the frequency with which competent pathologists have made a histological diagnosis merely of non-specific synovitis. You encourage me to tackle the problem again.

DR. PolLEY: The generous and thoughtful comments of our orthopaedic friends, such as Dr. Key, are very welcome. It seems to me that the essence of the remarks of 
Dr. Key and also of Dr. McEwen is that we still have much to learn about synovial pathology.

In addition to the pathologist's report, it has been helpful to us as clinicians to study the tissue obtained by punch biopsy of the synovia in attempts to correlate both clinical and pathological findings. We like to think that in this way we may accentuate the interests of pathologists in rheumatic diseases and thereby further benefit ourselves as clinicians.

Like other technical procedures, facility with the punch biopsy of synovia is improved by experience. However, the technique is not a difficult one; it may be helpful to use this procedure initially on the thick boggy synovia found in some rheumatoid joints. Initial use of general anaesthesia also may help instill confidence in an ability to perform the procedure and thereby facilitate improvement of the technique.

My colleagues and I hope that many of you will be as intrigued as we are by the potentialities of further investigation with punch biopsy of synovia. Your interest and efforts may result in further understanding of many little understood aspects of rheumatology.

Local Anti-Rheumatic Effectiveness of Higher Esters and Analogues of Hydrocortisone. By J. L. Hollander, E. M. Brown, R. A. Jessar, N. SMukler, L. Udell, and M. A. Bowie, Philadelphia, Pa.*

Intra-articular hydrocortisone acetate therapy has been limited in usefulness for some arthritic patients because the beneficial effect was too transitory. Our previous studies have shown that the injected hormone is absorbed and retained by the synovial lining of the joint without splitting the ester. Because less soluble analogues or esters of hydrocortisone might thus have a longer effect, certain compounds were given intensive clinical trials.

Hydrocortisone t-butyl acetate was injected into the rheumatoid or osteo-arthritic joints of more than 100 patients who had previously experienced only minimal or transitory local relief after the same dose of hydrocortisone acetate. The patients were not informed of the substitution. In approximately two-thirds of the cases the degree of subjective and objective improvement was appreciably increased, and the duration of effectiveness multiplied from two to ten times. In most of the remaining one-third no difference was noted, but in a few the effectiveness appeared less.

Allo-dihydro-hydrocortisone was similarly assayed in twelve cases, but was found completely ineffective in all. Another analogue, 9-alpha-chloro hydrocortisone, was slightly more effective than hydrocortisone acetate in seventeen cases. Comparative results from hydrocortisone caprylate and hydrocortisone benzoate, assayed as above, were also obtained.

The results so far indicate that the use of certain less soluble esters of hydrocortisone may increase the practicability of intra-articular hydrocortisone therapy.

Discussion.-DR. Ivan F. Duff (Ann Arbor, Mich.): We have compared the effectiveness of intra-articular hydrocortisone acetate, hydrocortisone t-butyl acetate and a free alcohol of hydrocortisone; the steroid dosage varied from 37.5 to $50 \mathrm{mg}$. Our results confirm those described by Dr. Hollander. Approximately 50 per cent. of a comparable group of patients with active rheumatoid

* See also p. 297 of this issue. arthritis receiving the hydrocortisone acetate or hydro-市 cortisone (free alcohol) obtained clinical benefit lasting from 4 to 10 days. By way of contrast, 50 per cent. of those receiving injections of hydrocortisone t-butyl acetate reported symptomatic relief lasting from 11 to 20 days.

Dr. Richard H. Freyberg (New York, N. Y.): At thes? suggestion of Dr. Hollander and through the kindo co-operation of Dr. Alpert, our research group has had an opportunity of observing the effect of the intraarticular injection of hydrocortisone t-butyl acetate,,$\vec{\gamma}$ compared with the effect in patients who had also received hydrocortisone acetate suspension intra-articularly.

Our series is rather small, only eighteen patients, alis with rheumatoid arthritis, of whom sixteen had injections $\overrightarrow{0}$ into the knees, and the other two into the hips-anaverage of three injections of t-butyl acetate in each case. $\vec{c}$

Our results in regard to duration of improvement, $\omega$ time of initial onset of improvement, and degree of improvement, are as follows:

Duration.-Eleven of the eighteen patients (61 percent.) had the same length of benefit with t-butyl acetate as they had with hydrocortisone acetate suspension.

In seven patients (39 per cent.) there was a significant $\omega$ increase in the duration of benefit, but in no instance did it exceed 200 per cent. of that produced by hydrocortisone acetate. The results were quite consistent, with repeatedinjections in the same patient.

Speed of Effect.-Initial benefit was a little slowero with the t-butyl acetate preparation. Sometimes thered was a 12 to $24 \mathrm{hr}$ delay in response.

Degree of Benefit.-In eleven of the eighteen patientsD (61 per cent.) we considered the degree of benefit to be the same. In seven (39 per cent.) there was a slight $20 \overrightarrow{0}$ moderate increase in the degree of relief obtained.

Our observations agree quite well with Dr. Hollanders

There is about a 40 per cent. chance of obtainings moderately increased degree of benefit, and about thes same chance of a significantly prolonged benefit from? hydrocortisone t-butyl acetate as compared with hydrocortisone acetate. In a few of the patients in whom there was no benefit from injections of hydrocortisonea acetate, moderately good results followed the injection of t-butyl hydrocortisone acetate.

DR. Hollander: I think that the results presented bys the other groups, all things considered, are quite in agreement. We always expect the fellow who reports it first to be the most optimistic. Our series was larger, andw it is very easy, in smaller groups, to get a stretch of patients who are not very good responders.

In our own group, each of us took a series of our own cases and did not total them up until the end. It was surprising the variation percentage-wise in degree of improvement and duration of improvement among our own group, before we lumped them all together. One of us had only 40 per cent. of the patients receiving considerable superiority from the hydrocortisone t-butyt acetate, and others of us obtained as high as 70 per cent

I think if we say 40 to 50 per cent. do definitely achievo better results from hydrocortisone t-butyl acetate as compared with the acetate, we are probably safe. WeN are still looking for something that acts longer and better

Suppressive, as compared with Analgesic Hormonat Therapy, in Patients with Rheumatoid Arthritis. *o By Laurance W. Kinsell, Oakland, Calif. One may elect to use one of at least four possible?

* See also p. 307 of this issue. 
procedures in the application of hormonal therapy to patients with rheumatoid arthritis:

1. Complete avoidance of such therapy.

2. A relaxed approach, in which the patient is instructed "to take two, three, or four tablets of cortisone if his joints hurt".

3. Carefully controlled administration of ACTHcortisone in conjunction with salicylates, the objective being minimal hormonal dosage compatible with reasonable activity and comfort.

4. Intensive initial hormonal therapy under precise hospital control, the objective being the production of a complete quiescence of inflammation within one week, as evidenced by disappearance of pain, swelling, and normalization of the sedimentation rate, and maintenance of the remission with minimal effective dosage.

All responsible physicians who treat patients with arthritis will agree that the second course is to be avoided under any circumstances. Agreement stops here.

The fourth procedure has been used by us in more than forty patients with rheumatoid arthritis, in the course of the past 4 years or so. Initial therapy consists of intravenous $\mathrm{ACTH}$, usually in conjunction with oral cortisone or hydrocortisone. When the sedimentation rate has become normal, the dosage is gradually tapered and the patient is usually discharged from the hospital at the end of 2 weeks, on maintenance dosage. In the months which follow, the dosage is further reduced as the patient's progress permits. The net results of such therapy are better than those obtained with the third or "super-aspirin technique" noted above. If such suppressive therapy is to be used, a precise programme must be followed, including particularly the use of diets designed to minimize the untoward effects of long-term hormonal therapy.

Discussion.-DR. Morris ZIFF (New York, N.Y.): I should like to know in what percentage of his patients Dr. Kinsell has been able to bring the sedimentation rate to normal. This, in our experience, has been a difficult thing to accomplish.

Dr. William H. Goodson, JR. (Kansas City, Mo.): In what form does Dr. Kinsell give protein and how does he get his patients to take that much?

Dr. Charles Ragan (New York, N.Y.): How many patients had gastro-intestinal intolerance?

DR. H. F. WEST (Sheffield, England): Has anyone else found extra wide variations in sedimentation rate when the proportion of protein was changed, or when the diet was changed to fats with no carbohydrate?

Dr. Edward F. Rosenberg (Chicago, Ill.): Why did Dr. Kinsell have almost 16 per cent. incidence of psychosis?

Dr. Theodore B. Bayles (Boston, Mass.): Do I understand that Dr. Kinsell is giving ACTH and cortisone concomitantly?

DR. KINSELL: The form of protein in the diet presents a difficult problem from the anaesthetic standpoint. It is not easy to give a diet of 100 to $150 \mathrm{~g}$. protein and still have a low sodium intake.

We have two general types of diet. In one of them we use synthetic protein supplements (that is, either desalted milk or desalted skimmed milk), and large amounts of washed cottage cheese. In the other, very large amounts of nuts are used because they are low in sodium and high in protein of excellent biological value.

We have five standard diets ranging from 1,400 to 3,000 calories. The patient receives adequate indoctrinations in diet while he is in the hospital.

The high incidence of both gastro-intestinal intolerance and psychosis is unquestionably due to the large dosage in many patients. It is in such patients that we have had to "back out". We know that a certain proportion of patients will be unable to continue with the high dosage necessary for complete suppression.

Regarding diet and 17-ketosteroids, as far as I know, no one else has administered formula diets with this amount of fats and no carbohydrate. No mixed diet contains this vast amount of fat, high protein, and no carbohydrate. We used Lilly's enteric-coated 1-g. tablets of potassium chloride.

The key to the problem of reducing the E.S.R. to normal is continuous intravenous ACTH with as much as 600 to $800 \mathrm{mg}$. cortisone daily in addition.

We either get the E.S.R. down to normal or we discontinue therapy because the patient manifests one of two major complications (psychosis or gastro-intestinal trouble). The E.S.R. was, in fact, brought down to normal in 37 patients in our series of forty.

For long-term maintenance, any patient that requires more than $50 \mathrm{mg}$. cortisone daily is given both ACTH and cortisone. For patients who are maintained on less, we usually give cortisone alone, for the reason that it can be given orally. We are worried about adrenal atrophy.

In patients whose ACTH response curves are subnormal, even less than $50 \mathrm{mg}$. daily, we give both.

Natural History of Haemolytic Streptococcal Infection in Childhood. By Lowell A. RaNTz, San Francisco, Calif.

A 4-year study has defined the natural history of haemolytic streptococcal disease in childhood. Infection and re-infection by these organisms during the first 4 years of life was a commonplace. During this period the clinical illness was characterized by the lack of an acute onset, by low-grade or absent fever, by rhinorrhoea, by a protracted unself-limiting course, and by the occurrence of frequent suppurative complications. Antibody production was feeble.

After the fourth year the disease pattern changed so that progressively more of the infections were associated with an acute febrile onset, sore throat, exudative tonsillitis and pharyngitis, skin rash, and a vigorous antibody response.

Rheumatic fever and lesser manifestations of the rheumatic state occurred after streptococcal infection in children more than 4 years old, but were never observed in younger children.

Evidence has been obtained which supports but does not establish the validity of the hypothesis that the changing patterns of clinical response to haemolytic streptococci are the result of repeated infection by these organisms with an alteration in tissue response, presumably on an immunological basis.

Discussion.-Dr. Currier McEwen (New York, N. Y.): Do you mean that, once having had streptococcal infection, were the children more apt to have other infections, or didn't you say that? 
DR. RANTZ: Yes. I am not sure whether these are statistically acceptable values because the group is fairly small, but consistently throughout this investigation we were impressed with the fact that once a child had had haemolytic streptococcal infection he was subject to other infections more often than those who had not had streptococcal disease. They seemed more susceptible, but I do not think we can settle the problem.

Dr. Currier McEwen: One more question that follows naturally from the other. Your streptococci were typed. Can you say whether the new infections were due to other types or might they have been flare-ups due to a carrier-state?

DR. RANTZ: Wherever it was possible to do typing we did so. Unfortunately, in this area, as throughout the United States, many of the civilian strains are untypable. We also had evidence of new antibody responses in practically all cases.

Dr. T. DuCKetT Jones (New York, N.Y.): Did any of these children have glomerulo-nephritis, and, if so, when did it come on, and were they all Type 12?

Dr. RANTZ: None of the children had glomerulonephritis, in spite of the fact there were twelve welldefined cases of Type-12 infection. So, I have no information about glomerulo-nephritis in this series, but some years ago we had glomerulo-nephritis appearing in very small children. I have had several cases of glomerulo-nephritis in children under 2 years old, which is different from the pattern of rheumatic fever, or seemed so to me.

President Ragan: Did two infections with Type 12 take place or was that the same infection over a 2 -month period?

DR. RANTZ: It was the same.

DR. JoSEPH J. Bunim (Bethesda, Md): Were suppurative sequelae of haemolytic streptococcal infections in the older children in any way predicated on the antibody response.

DR. RANTZ: I think so, but I can't positively prove it. In other words, I believe that is probably right, and it is probably the changes in immunological response that are responsible for these complications, but, as I said, I do not know how to prove it. Wherever you look you find hints, an association with more intense antibody response in individuals who develop rheumatic fever.

DR. J. A. LichTY (Denver, Col.): Has Dr. Rantz any idea whether any of these children might be going to be rheumatics, from any of the studies. We should so much like to be able to spot these children before they get their first attack.

Dr. Rantz: No, I don't think so.

Dr. William H. Goodson, JR. (Kansas City, Mo.): I have the impression that Dr. Rantz does not see tonsillitis and otitis media in small children. Out in the neighbourhood where we live, acute pharyngotonsillitis with exudate on the tonsils, and an occasional mastoid infection are very common in children between the ages of 6 and 18 months. The same children, followed over a period of years, may have re-infections, farther and farther apart, until they get to be 6 or more years old, when the re-infections practically disappear.

DR. RANTZ: I thought I brought out that suppurative complications with otitis media were extremely common in such small children. We were unable to satisfy ourselves, though, when we examined the pharynx of such small babies that there was really exudative type tonsillitis of the adult type.

President Ragan: Can you, from your data, state definitively whether this difference in antibody response $\Rightarrow$ after the age of 4 years is due to previous re-infection 0 with streptococci or it is due to ageing?

DR. RANTZ: I can't positively state that.

President Ragan: Have you any patients that did not have streptococcal infection who had a good antibody response at the age of 4 years?

DR. RANTZ: We did not have a study so defined; we were following many patients into this older age group $\overrightarrow{0}$ from infancy.

President Ragan: In a clinic for healthy babies, $\vec{\omega}$ couldn't it be determined?

DR. RANTZ: I think you could design something that would determine it, but it was not done in this study.

Functional Status of the Pituitary-Adrenal System in Rheumatic Fever. By VINCENT C. KelleY, Salt Lake City, Utah (by invitation).

The circulating concentrations of 17-hydroxycortico- 을 steroids, the predominant hormones produced by the $\vec{r}$ adrenal cortex, are abnormal in rheumatic fever patients. The concentrations of these steroids observed in patients $\underset{\mathbb{Q}}{\mathbb{Q}}$ in various phases of rheumatic fever are related to the duration of illness.

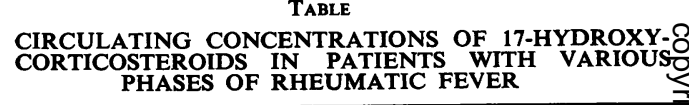

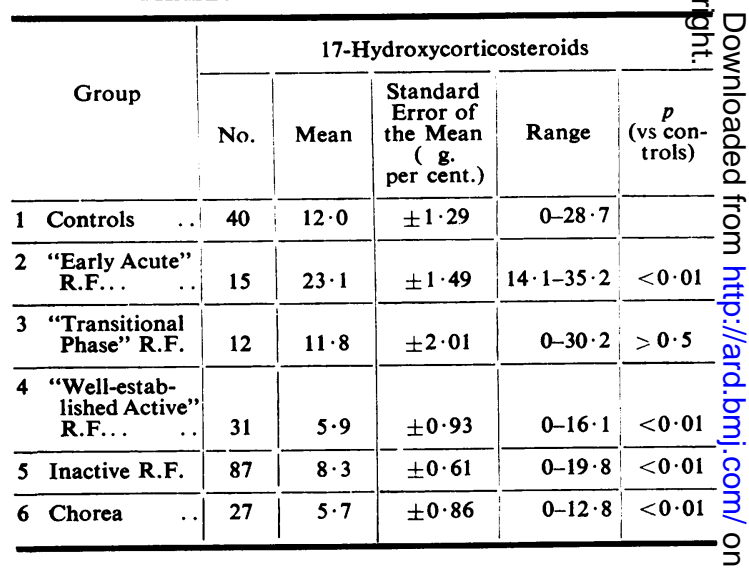

During the first week of rheumatic activity ("early $>$ acute") the 17-hydroxycorticosteroids are significantly을. elevated. During the second week ("transitional phase") the steroid values are extremely variable, whereas after. two weeks of rheumatic activity, these values are uniform- $N$ ly low. These values are likewise uniformly low in patients $\mathrm{N}$ with inactive rheumatic fever and with chorea.

On the other hand, circulating concentrations of endogenous ACTH are normal in the early acute phase bute elevated in patients with well-established rheumatic fever, inactive rheumatic fever, and chorea. In these patients? the equilibrium state of low 17-hydroxycorticosteroid 
and high ACTH concentration is interpreted as indicating adrenal cortical insufficiency. That this adrenal insufficiency is relative rather than absolute is indicated by the adequate steroid response of these patients to sufficient ACTH stimulation. In response to an intramuscular dose of 25 I.U. ACTH, rheumatic patients exhibited a mean plasma steroid increase of $26 \mu \mathrm{g}$. per cent. as compared with a mean increase of $17 \cdot 8 \mu \mathrm{g}$. per cent. in normal children. That these patients can respond likewise to sufficient endogenous ACTH stimulation is illustrated by case examples of steroid levels raised in response to stress.

Hereditary factors may affect rheumatic fever susceptibility. There may be a place for hormone therapy in rheumatic fever.

Discussion.-President Ragan: Were the patients with the low circulating levels of 17-hydroxycorticosteroids-whom you said were untreated-on salicylate?

Dr. Charles L. Steinberg (Rochester, Minn.): Do you consider a hydrocortisone response as a non-specific reaction to stress, and have you studied this effect in other infectious diseases? Was the renal insufficiency produced by this type of infection followed by the level of circulating eosinophils?

Dr. Theodore B. Bayles (Boston, Mass.): What do you mean by "inactive" rheumatic fever. Does a patient who had active rheumatic fever at the age of $\mathbf{1 0}$ years, who is now 20 years of age, still have abnormally low steroid levels? I think that should be cleared up.

Dr. Currier McEwen (New York, N.Y.): From your data, I should estimate an average dose of cortisone for these children would be about $200 \mathrm{mg}$. daily. Is that correct?

Secondly, have you any data on the possible levels of ACTH or cortisone in patients with active rheumatoid arthritis, just as a comparison?

Dr. Paul J. Bilka (Minneapolis, Minn.): Dr. Dougherty said that they could diagnose adrenal insufficiency by looking at a blood smear and checking the lymphocytes. Did Dr. Kelley find these altered lymphocytes in these patients with low 17-hydroxycorticosteroids? It would be of great help to all of us, if we could diagnose adrenal insufficiency by that simple means.

DR. T. DuCketT Jones (New York, N.Y.): What type of murmur are you talking about; if significant murmurs, were they of the same type in the two groups?

President Ragan: What did salicylates do to the blood hydroxycorticosteroid level?

DR. Kelley: In answer to Dr. Ragan's first question, the levels of 17-hydroxycorticosteroids presented were in untreated patients, none of whom had received any highdose salicylate therapy. They were patients as they arrived at our hospital on referral. Some of them had had an occasional aspirin tablet before they came in, but none had received hormone therapy or high-dose salicylate therapy.

President Ragan: During the 16 weeks they were not on salicylate?

DR. Kelley: No. That was the time since the onset of illness. They received no therapy whatever.

In answer to Dr. Bayles: We have defined the patient with "inactive" rheumatic fever as one who has been seen by one of us in the University Department of Paediatrics or the state rheumatic fever clinics during an acute attack of rheumatic fever, who has been for at least 6 months symptom-free, and who on the day of the determination had a normal sedimentation rate and no clinical evidence of activity. Some of these have been inactive for as long as 5 or 6 years. We think the low steroid level persists after a patient has once had rheumatic fever, and we are speculating whether it existed before the attack of rheumatic fever, and whether this might be the factor that made him susceptible. We have a few patients who have never had a diagnosable attack of rheumatic fever, but have developed cardiac murmurs and cardiac enlargement over a period of years, who have the same hormone pattern as is present in rheumatic fever patients with low steroid levels and high ACTH levels.

In answer to Dr. Steinberg: If I interpret your question properly, we think the rise in 17-hydroxycorticosteroid level, which occurs during the first week of rheumatic fever, is a non-specific reaction to "stress", just like the rise which occurs in acute meningitis or other acute, severe disease. The difference is that in the other diseases, after this early phase, the steroid levels return to normal and not to sub-normal levels as in rheumatic patients. We feel that the reason for this may be that the rheumatic patient has had a low "normal" level before the onset of illness. With the "stress" he develops elevated levels, which later return to sub-normal levels. We know this to be the case in a second attack of rheumatic fever. We have followed several patients who had a first attack, were included in our inactive rheumatic fever group, and then had a recurrence. While they were in the inactive stage they had low steroid levels, and during a recurrence they followed the same pattern as that seen in other patients during an acute attack.

In answer to Dr. McEwen: The average dose, according to our schedule, depending upon the size of the patient, is about 2.5 to $3 \mathrm{mg}$. cortisone per lb. This would amount to an initial dose of about 200 to $300 \mathrm{mg}$. cortisone daily.

We have about a dozen juvenile rheumatoid arthritics. Their steroid levels are consistently low as in rheumatic fever, but not quite so low as in our small group.

I have no answer to the question whether the lymphocytes are altered. If Dr. Dougherty is here he may like to comment. Not being haematologists, we have not used the lymphocyte response as an indicator of the presence or absence of adrenal insufficiency.

Dr. Jones asked about the murmurs present in these patients. With one exception, all had carditis as a major symptom in their acute attacks of rheumatic fever. Several had diastolic murmurs, several had more than one murmur, and all had at least Grade II systolic murmurs.

In the follow-up study we consider any detectable murmur. At the one-year follow-up the two hormonetreated patients had murmurs, which were only audible in certain positions. When we say "no murmur", it means none of us were able to find any murmur, and several different workers have examined each patient.

As to the severity of illness in the two groups, this was not a "blind control" series, but the more severe cases are treated with hormones, so that distortion of the series is in that direction. Occasional patients who were referred specifically for hormone therapy, or insisted upon having it, were included in the hormone group.

In answer to Dr. Ragan's last question, the effect of salicylates on the blood steroid levels is a very interesting and very long story. Patients with salicylate intoxication 
have extremely hign levels of circulating steroids, as we have reported. This has been found consistently in every previously normal patient with salicylate intoxication. However, in rheumatic fever patients who are treated with salicylates to the point of intoxication, the steroid levels are not raised, but appear to be below normal.

We have taken a large group of normal volunteer medical students and treated them with salicylates in various dosage schedules, corresponding to the schedules used in rheumatic fever. In these subjects we found no consistent elevation of steroid levels at any particular time after administration. However, we were able to demonstrate a raised steroid level at some time during the following 12 hours which was greater than the normal diurnal variation. I think it is more important that we demonstrate an increased rate of removal of steroids from the circulation after the administration of salicylate. This is attributable to some mechanism other than urinary excretion. We feel it probably indicates an increased rate of utilization, but we have no data to substantiate that interpretation.

If I may mention one more thing-we have recently done some studies in which we inject Compound $F$ alcohol and follow the rate of its disappearance from the blood. In contrast to what we expected, the Compound F disappears about one-half as rapidly from the blood of rheumatics as it does from normal individuals. Secondly, when salicylates are administered 2 hours before the Compound F, we can demonstrate an increased release of steroids from the adrenal cortex, but also an increased rate of disappearance of the steroids from the blood, so that the curve extrapolates to 0 after about $2 \frac{1}{2}$ hours as opposed to 5 or 6 hours without salicylates.

Prophylaxis against Group-A Streptococci in Rheumatic Fever Patients by the Use of Single Monthly Injections of $\mathbf{N}, \mathbf{N}$ ' Dibenzylethylenediamine Dipenicillin G (Bicillin). By Gene H. Stollerman, Jerome H. RUSOFF, and ILSE HIRSCHFELD, Irvington-on-Hudson, New York.

Single intramuscular injections of $1 \cdot 2$ million units of N,N' Dibenzylethylenediamine Dipenicillin G (Bicillin) were administered for two successive years to a group of 138 out-patients, recently recovered from acute rheumatic fever, and to $\mathbf{2 7 0}$ patients hospitalized at Irvington House in the acute and convalescent stages of the disease.

No recurrences of rheumatic fever were observed in either group. In a comparable series, two of 111 patients who received penicillin orally $(200,000$ units daily), and five of 79 patients who received sulphadiazine orally (1 $\mathrm{g}$. daily), suffered frank rheumatic recurrences.

Of 2,052 throat cultures made monthly from outpatients receiving Bicillin injections, only three were positive for Group-A streptococci. Of 2,010 determinations of antistreptolysin 0 titres made in the same group, a significant rise in titre was noted only twice. During the spring of 1953, 27 per cent. of a control group of clinic patients were found to have Group-A streptococci in their throats.

Between 50 and 75 per cent. of patients receiving Bicillin, who were tested at various times during the study, were found to have detectable levels of penicillin in their sera as long as 4 weeks after an injection.
Of 35 patients found to be carriers of Group-A streptococci upon admission to the study, 31 were cured of the carrier state by a single intramuscular injection of $\square$ Bicillin. The remaining four showed bacterial relapse after variable periods but were cured by a second $\vec{F}$ injection.

All patients admitted to the study without clinical $\stackrel{ }{C}$ evidence of heart disease remained normal during the $\underline{\underline{O}}$ 2-year period of prophylaxis. New valvular lesions did $\frac{\sigma}{\partial}$

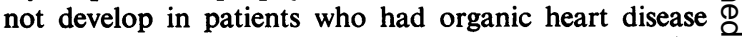
initially. Two patients in this group had progressive change in murmurs in the absence of intercurrent streptococcal infection.

4,073 injections were administered to 408 patients during the study. One patient developed urticaria, $\vec{\omega}$ which subsided within 4 days, and treatment had to be permanently discontinued in one patient. Although $\frac{\bar{\alpha}}{2}$ local pain, tenderness, and induration, usually lasting $\vec{\omega}$ 24 to 48 hours, were common, no patient developed an abscess or other serious reaction at the injection site.

Discussion.-DR. JONES (Columbus, Ohio): Did the patients develop any other type of infection, and was there a normal response to penicillin therapy?

DR. JoSEPH J. Bunim (Bethesda, Md): In view of the type of follow-up carried out in these cases, is it possible that some might have developed some transitory allergic reaction which escaped detection?

Dr. T. DuCKetT Jones (New York, N.Y.): In the new statement the American Council on Rheumatic Fever $\vec{\theta}$ is contemplating putting out, the committee, for tre time being, favours parenteral as opposed to ora penicillin. This has resulted in a surprising antagonis from paediatricians.

We have as yet no data about the sensitivities in adults, and I should like to ask Dr. Stollerman if he has any ideas about this, and whether any patients developed L.E. cells.

Also, did the three patients who had a progression of $\varrho$ heart disease-this is a relatively small group-have $\vec{\overrightarrow{ }}$ continuous rheumatic fever, or does he infer that, even on the long-acting penicillin prophylaxis, there were subclinical recurrences in a very few.

In the regressions with decrease in heart disease and? those with the disappearance of rheumatic heart disease, his percentages are almost identical with those reported by Dr. Bland and reported over a long period of years as regressing in a natural way without prophylaxis.

Dr. Currier McEwen (New York, N.Y.): I have been $\hat{\rho}$ disconcerted to find that some medical men have the 3 impression that because penicillin is long-acting when given intramuscularly, it also has some special virtue, in this regard, when given orally. Of course, the long- $>$ acting effect is obtained only when the repository peni-음 cillin is given intramuscularly.

DR. JOSEPH EDWARD WARREN (Pittsburgh, Pa): \% Dr. Stollerman has given us a comparison of recurrence $N$ rates when one uses sulpha drugs or oral penicillin, and 0 I believe it is unfair to the only competitive regime which $\omega$ is oral penicillin. For comparison we need some data on the relative toxicity of oral penicillin. Many more patients must be studied before we can distinguish between a recurrence rate of only two patients in $130, \mathbb{\mathscr { Q }}$ and none in his group.

Dr. Stollerman: In answer to Dr. Bunim: we included 
269 hospitalized patients in this series, in addition to the 145 out-patients, for the express purpose of observing them closely daily for any type of allergic manifestation. The incidence of reactions was no different in the inpatients and in the out-patients.

In addition, we performed skin tests at the end of 6 months of Bicillin therapy on 100 patients to see whether they had acquired skin sensitivity to this compound. None were positive. We recognize the limited value of skin testing in detecting penicillin hypersensitivity.

With regard to the question of other infections, I think it is important to mention that there were two patients who developed subacute bacterial endocarditis during this period of prophylaxis. In both instances the organism was found to be sensitive to penicillin and both patients were cured promptly by the usual 4-week course of large parenteral doses of penicillin.

Other unrelated infections included two mild cases of staphylococcal otitis media and pharyngitis, which were cleared up by a course of procaine penicillin $\mathbf{G}$.

In answer to Dr. Jones: I think the antagonism to parenteral penicillin results from the traumatic experience of many doctors who have observed serum sickness in patients receiving injections of penicillin.

I should like to emphasize that we are not trying to pit one form of prophylaxis against another. We are trying to demonstrate a new technique that is available in situations where oral prophylaxis often fails. Such a situation often arises with an out-patient group, where the reliability of oral prophylaxis cannot be guaranteed. We do not introduce this method as a form of prophylaxis to replace completely the administration of penicillin orally. We introduce it as an addition to the practitioner's armamentarium where the risk of recurrence is very great. We think that the risk of penicillin sensitivity when compared to the risk of recurrences in the type of population with which we are dealing is well worth taking. We have little data on the incidence of hypersensitivity in adults who have received Bicillin.

A search for lupus erythematosus-like cells in the blood of fifty patients who had received Bicillin for 6 months was made by one of our staff who was engaged in another study, and no such cells were found.

I cannot at present answer the question whether continuous low-grade rheumatic fever is responsible for the progression of heart disease in the three patients mentioned. I think it will take extensive and prolonged observation to compare this series with the much longer series of Jones and Bland.

In answer to Dr. McEwen, I think carefully controlled studies of the true incidence of penicillin reactions after parenteral as compared with oral administration are sorely needed. It is our impression also that penicillin given orally has a very low incidence of toxicity; we are not sure whether the reaction rates after parenteral administration are a little bit higher.

Finally, I agree entirely with Dr. Warren that this data by no means provides an adequate comparison of parenteral versus oral prophylaxis. We now have a large-scale controlled study under way, which will yield more extensive data on this problem.

Rheumatic Heart Disease in Colorado School Children. By H. J. Dodge and J. A. Lichty, Denver, Col.

A state-wide study of the prevalance of rheumatic heart disease was made in Colorado's 6th grade children. This was prompted by the high mortality rate from this disease in the Rocky Mountain states and its reported high incidence in military posts in this region. The findings of a careful clinical examination of some 11,000 unselected 6 th graders* revealed only 74 (0.66 per cent.) cases of definite rheumatic heart disease. For half of these cases there was no diagnosis or history of previous rheumatic fever; 63 additional children were suspected of having some type of heart disease.

Analysis of the data revealed an unusually high prevalence of rheumatic heart disease in the SpanishAmerican population, in rural areas, and in crowded homes. No association was found with altitude or geographical situation.

Parents of all children with definite or suspected heart disease (all types) received letters recommending further diagnosis and treatment by the family physician. After 2 years, follow-up information was obtained by questionnaires distributed to the families and physicians of $\mathbf{3 1 5}$ such children. Where possible, hospital records were also reviewed. Some information was obtained for 50 per cent. of the children, half of whom were seen at least once by a physician. For children with definite heart disease, the diagnosis had been changed in only 7 per cent. of a group receiving either special diagnostic tests or cardiologist consultation. In contrast, it had changed in 45 per cent. of children not receiving these services. One possible explanation is that family physicians are misinterpreting heart sounds.

The follow-up information revealed that only $14 \cdot 5$ per cent. of children with definite rheumatic heart disease were receiving drug prophylaxis.

Discussion.-Dr. JoHn HubBard (Philadelphia, $P a$ ): Was the subsequent diagnosis and the original diagnosis made by the same individual or the same team, or did it shift, perhaps, from a team to a family physician diagnosis?

Could some idea be given of the type of prophylaxis recommended through this group?

Dr. LICHTY: I think the important thing is that the follow-up was done by a family physician. The team has not had a chance to go out to re-study these children.

Most of the children were on sulpha drugs, but I do not believe that we have any preference for any particular prophylactic regime in our state.

\section{Mechanisms involved in the Production of Fibrinoid Necrosis by Endotoxins. By LewIS Thomas, Minneapolis, Minn.}

The basic lesion in the so-called "collagen" diseases is the deposition of fibrinoid material in tissues. The prototype of this group is disseminated lupus erythematosus, in which extensive deposits of fibrinoid occur in the lumen and walls of blood vessels and in surrounding connective tissues. The closest approximation to this histopathological situation obtainable in experimental animals is the generalized Shwartzman reaction, which is produced in rabbits by two intravenous injections of endotoxin from various Gram-negative bacteria. Within a few hours of the second injection, masses of material resembling fibrinoid appear in the glomerular capillaries, resulting in bilateral cortical necrosis of the kidneys.

* Maresh, G. J., Dodge, H. J., and Lichty, J. A. (1952). J. Amer. med. Ass., 149, 802. 
Under certain conditions, similar material appears in the coronary arteries, in association with varying degrees of necrosis of the vessel walls, and it also occurs as vegetations in the mitral and aortic valves.

Serial histological studies of kidneys during the development of the generalized Shwartzman reaction showed that fibrinoid appears within the lumen of glomerular capillaries before there is any evidence of vessel wall damage or necrosis. It is considered probable that the material is derived from the circulating blood. Heparin, which prevents the generalized Shwartzman reaction, also prevents the appearance of fibrinoid in the glomeruli.

Liquoid (Na polyanethol sulphonate), a synthetic polymer, has the property of precipitating fibrinogen from plasma. When injected by vein in combination with endotoxin, it causes a greater than 1,000-fold enhancement of the lethal action of endotoxin, and typical lesions of the generalized Shwartzman reaction occur in all animals. This reaction is completely prevented by prior heparinization.

It is believed that the two stages of the generalized Shwartzman reaction involve the appearance of an abnormal coagulable material in the circulating blood, followed by precipitation of this material within the lumen and the walls of the blood vessels.

Discussion.-DR. Evan Calkins (Boston, Mass.): Does the heparin go down in the precipitate or is it in the supernate?

DR. Morris ZIfF (New York, N.Y.): I compliment Dr. Thomas on this excellent paper; I must point out, however, that fibrinoid in different tissues and in different diseases may have an entirely different composition.

Dr. C. F. McLean (Berkeley, Calif.): Has this anything to do with the so-called fibrinogen $B$ ?

Dr. Morris ZifF (New York, N.Y.): Kellgren, Ball, Astbury, and co-workers, examining the nodules of rheumatoid arthritis, found no evidence of the $x$-ray pattern of fibrin in this type of fibrinoid.

Dr. J. Albert Key (St. Louis, Mo.): Do you think that this intravascular fibrinoid is the same material as occurs extravascularly around joints and in nodules?

Dr. Thomas: Of the possible differences in fibrinoid in different tissue situations, I think it is possible that fibrinogen might conceivably be precipitated by material giving staining reactions other than polysaccharides, for example, nucleic acid material. There is heparin in the precipitate. It is loosely bound, and easy to get off. It has to be there for the precipitate to go down.

Regarding fibrinogen B, I think there is possibly some relationship between this material and the so-called cold precipitable fraction of semi-purified fibrinogen loss. However, the main difference is, that in our material heparin must be present for full precipitation to occur.

Effect of Hypophysectomy and Growth Hormone on Radioactive Sulphur Uptake in Cartilage. By Charles W. Denko, Allan T. Kenyon, and Delbert M. Bergenstal, Chicago, Ill.

Factors affecting the rate of fixation of radioactive sulphur, $\mathrm{S}^{35}$, into tissues have aroused our interest. Radiosulphur is organically bound into many tissues of normal animals, especially cartilage and other connective tissues. Its incorporation into chondroitin sulphate has been demonstrated.

Young female rats, hypophysectomized and normal, were used in a study to determine the effects of growth hormone on $\mathbf{S}^{35}$ fixation. To study the synthetic activity of cartilage repeated injections of $S^{35}$ were given intraperitoneally with and without growth hormone $\frac{\overline{\bar{D}}}{\mathrm{D}}$ (Armour) daily for 8 days. One day after the last $\frac{\rho}{\partial}$

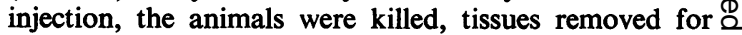
study, washed, sulphur precipitated as barium sulphate, and radioactivity determined as a measure of $\mathbf{S}^{\mathbf{3 5}}$ fixation in the tissues.

Cartilage, especially the xiphoid, costal, and tibial $\overrightarrow{\vec{H}}$ articular (as the tibial cap), was found to contain higher $\omega$ concentrations of $\mathrm{S}^{35}$ than the other tissues studied. Hypophysectomy decreased the rate of fixation of $\bar{Q}$ sulphur in these tissues approximately 25 to 80 per $\vec{\omega}$ cent. below that found in normal animals. Growth $\rightarrow$ hormone administered to hypophysectomized rats caused $\omega$

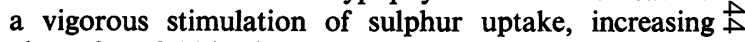
about four-fold in the costal cartilage.

Normal animals receiving similar injections of growth $\stackrel{\vec{J}}{\rightarrow}$ hormone showed a decrease in the fixation of $S^{35}$ by $\square$ tissues, ranging to 25 per cent. below normal levels.

Thyrotrophin was present as a contaminant in small amounts in the growth hormone preparation used. $\frac{\partial}{\sigma}$ However, tests of its effects at this contaminating level demonstrated no comparable or appreciable effect on $\vec{\omega}$ $\mathbf{S}^{\mathbf{3 5}}$ fixation in cartilage.

Discussion.-Dr. J. Albert Key (St. Louis, Mo Is there any evidence that there is any increased grow at the rib cartilage as evidenced by deformity of the chest in these animals?

Dr. Morris ZIFF (New York, N.Y.): What is the half- 응

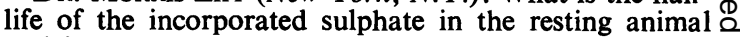
and in the hormone-treated animal?

These experiments seem to show that mucopoly- 윽 saccharides, unlike the collagen of connective tissue, do turn over in the adult animal.

Dr. Charles L. Steinberg (Rochester, N.Y.): This is a very interesting paper, particularly the emphasis on the effect of hypophysectomy on joints. Hypophysectomy results in splenic atrophy in certain animal experiments. We are familiar with the fact that splenomegaly occurs in 3

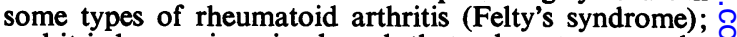
and it is known in animal work that splenectomy results in hypertrophy of the anterior lobe of the pituitary.

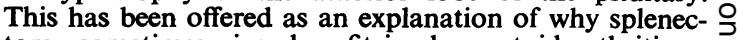
tomy sometimes gives benefit in rheumatoid arthritis.

Was there any change in the spleen, or atrophy, as a result of hypophysectomy, and was there any change in the uptake of radioactive sulphur in these cases?

DR. DENKo: In answer to Dr. Ziff, we are doing studies on the difference in half-life of incorporated sulphur ${ }^{35}$ in $\bigcirc$ treated and untreated animals, at the present time. In $\mathrm{\omega}$ the preliminary state, at 2-week levels, that is in animals $\sigma$ killed 2 weeks after the last dose, there appears to be no difference in the slope of the disintegration of the radioactive chondroitin sulphate.

We are continuing this study and have evidence that $\stackrel{\mathscr{S}}{?}$ makes us feel that, in the early stages of disintegration $\square$ it may not be enough to be detectable. But, in view of 
the long half-life of the incorporated material, we have carried on studies lasting up to 2 months. We must carry them on much longer than 2 weeks before we can give you a reliable answer to that question.

DR. Morris ZIFF (New York, N.Y.): Is all new formation, formation of new growth?

DR. DENKo: No. We have other data that indicate that not all new growth in a hypophysectomized animal at the age of 26 days has the same rate of sulphur fixation. Hypophysectomized animals at the age of 46 days, that is approximately 24 days after the hypophysis has been removed, have approximately the same fixation as rats aged 26 days receiving sulphur initially 4 days after hypophysectomy. There is no appreciable increase in the size of the animal, and there is no effect of growth hormone, or of any endocrine factor, as far as we can determine.

Consequently, we feel there may be a basic process such as trans-sulphation or trans-sulphation which occurs in living cartilage, without the influence of endocrine factors.

As to the evidence of increased growth of the rib cage by deformity of the rib cage, we do know there is some change in the character of the cartilage. In the hypophysectomized animals receiving growth hormone the costal cartilage becomes brittle and changes colour. It becomes more opaque and does not glisten as much, as if an ageing process had gone on.

Furthermore, in these animals there is a noticeable increase in the amount of bony spurring to be detected in a tibial cap.

With regard to the change in the spleen as a result of hypophysectomy, the spleen tissue is so inactive that sulphur uptake or sulphur fixation in the spleen cannot be utilized suitably for this study. However, we have noted a regression of many of the endocrine organs in the hypophysectomized animals. As far as the spleen is concerned directly, it looks the same, but the sulphur fixation cannot be reliably determined.

Size and Shape of Hyaluronic Acid. By B. Blumberg, G. Oster, and K. MeYer, New York, N.Y.

A study of the physical nature, i.e. size, shape, deformability, etc., of hyaluronic acid, an important constituent of the ground substances of connective tissue, might help in our understanding of the nature of the changes observed during varying conditions of health and disease.

The scattering of light by large molecules provides a method for studying the size, shape, molecular weight, and interaction of the particles. From these studies, the molecule of hyaluronic acid of umbilical cord (analytically protein-free) is found to be a particle of molecular weight about 8 million whose envelope is a sphere of diameter $2,000 \AA$ (similar to that reported by Ogston and Stanier using different physico-chemical techniques for a hyaluronic acid-protein complex containing 30 per cent. protein obtained from synovial fluid). The linear polysaccharide molecule is coiled in some fashion in this envelope and is surrounded by a large volume of water. Indeed, the anhydrous material represents only about 0.25 per cent. of the weight.

Ultracentrifuge studies give a sedimentation constant low for a particle of this size, suggesting that the particle is free draining, i.e. that the water can easily circulate through the mesh of linear hyaluronic acid. The diameter of the mesh "fibres" approximates to $10 \AA$.

The molecule shows flow birefringence, indicating that it is deformable in a sheer gradient, as is to be expected in such a swollen particle.

These observations are related to clinical findings, the gel-sol properties involved, and ion and water binding.

Inhibition of Cortisone Effect on Inflammation and Repair by Cartilage Extracts. By JoHN R. MARTIN, Raffeal Lattes, and Charles Ragan, New York, N.Y.

Previous communications from this department have shown that the inhibitory effect of cortisone on repair can be overcome by local infection. Recently cartilage extracts have been shown to have a similar effect.

Experimental Studies: The technique of gauze implantation and the cortisone schedule have been outlined previously. In the present work, the effect of cartilage upon the modification of the repair processes by cortisone was studied. Two suspensions were used, one containing powdered autoclaved beef tracheal cartilage, and the other fresh homogenized pig's knuckle cartilage. One group of animals received daily injections of the autoclaved suspension similarly. Daily injections of antibiotics were given. The remaining two groups were controls, receiving injections of the suspending vehicle instead of cortisone. At the end of 5 days, the animals were killed.

Results: Autoclaved Cartilage: The pledgets were partially adherent to the surrounding tissues in the cortisone-treated and control animals. The microscopic picture was identical in both, showing abundant granulation tissue.

Pig's Knuckle Cartilage: The pledgets were partially adherent in the cortisone-treated animals and more so in the controls. The microscopic picture showed a moderate reparative process around the pledget in the cortisone-treated animals which was, however, more abundant in the controls.

Bacterial cultures from the pledgets were sterile in 50 per cent. of each group.

Conclusions: Suspensions of cartilage are capable of suppressing the inhibition of repair by cortisone.

\section{An Epidemiologic Look at the Problem of Classification in the Field of Arthritis. By Sidney COBB, William Merchant, and Joseph Warren, Pittsburgh, Pa.}

Arthritis survey data have usually been unsatisfactory because they have been neither precise nor disease specific. We are now trying to develop a broadly applicable survey method from our studies with a population of 10,000 people in 3,000 families that have been selected at random from the Arsenal Health District of Pittsburgh. A household survey has identified a large number of persons with rheumatic complaints who are now under clinical study.

We find that persons with rheumatic symptoms far outnumber (6 to 1) those individuals fitting a classical disease description. The majority have not consulted 
a physician for these symptoms, suggesting that the sample differs from that seen in clinical practice.

A technique of charting signs and symptoms that help us to visualize this classification problem has been devised. Illustrative cases emphasize the difficulty of deciding when an atypical case is too atypical to be included.

There is an urgent need for limiting definitions. The limits must laterally define the boundaries between diseases and vertically the minimum severity at which the diagnosis is acceptable.

Discussion.-Dr. Charley J. SMyth (Denver, Col.): This paper is illustrative of the type of information that is long overdue. I am certain that our work in the future in case-finding and evaluating new drugs will have to go back to work of this type. The group are to be congratulated in presenting data of this sort, because we have no guideposts or index of the frequency of the various types of disease. In evaluating therapy we are confronted with the same problem.

Dr. Russell L. Cecil (New York, N.Y.): When the Committee on Criteria go over this problem, which is so important, they should give a great deal of attention to monarticular joint disease, a condition that, when I was on the consultation staff at the Veterans Hospital, worried me not a little. Generally, a soldier had come back from the Pacific with a monarticular pain, swelling, and sometimes moderate hydrops. There I sat looking at it, with young students around, and the young doctors waiting for me to make a diagnosis. Many a time I have been embarrassed because I did not know how to classify it.

Dr. Charles Ragan (New York, N.Y.): I, too, think this work is of fundamental importance.

Dr. Philip S. Hench (Rochester, Minn.): This careful study must surely have been a labour of love. It is very informative and gives us data of practical importance which we have long needed, a clinical summary we can accept with confidence.

Rheumatoid Arthritis with Remissions: A Study of Eighty Patients. By Charles L. Short, William E. REYNOLDS, and WALTER BAUER, Boston, Mass., and Jean M. Beauregard, Montreal, Canada. (Read by Dr. Bauer.)

Detailed information in regard to the course before hospital admission was obtained from 293 patients with rheumatoid arthritis representing consecutive admissions to a medical service, 80 , or 27 per cent., experienced one or more remissions, while in the remainder the course was essentially progressive.

The courses followed by each of the 80 patients who experienced remissions have been graphically portrayed. From these graphs, examples of which will be given, a simple classification of the differing course patterns was derived, based on the length of attacks and remissions. In the large majority of patients, attacks were "brief" (of one year's duration or less), with remissions either "brief" or longer than one year. In the remainder, attacks were "long" (over one year), with either "brief", or "long" remissions. While attacks of over one year were thus much less likely to be followed by remissions, instances were recorded of complete remissions after two to five years of active disease. In the whole group with intermittent course, about twice as much time was spent in remission as in exacerbation.

The remissions began throughout the year, with a peak in May, but exacerbations started more frequently in the colder months, a distribution corresponding to the available figures for the season of onset of rheumatoid arthritis. The rheumatoid arthritic is thus more likely to experience either a serious worsening of his disease or the actual onset of his arthritis in the colder than in the warmer half of the year, though it is not to be finally assumed that climatic changes are necessarily responsible.

Discussion.-Dr. Sidney CoBb (Pittsburgh, $\mathrm{Pa}$ ): As an epidemiologist I am not satisfied with the explanation of the seasonal distribution of any disease, infectious or otherwise, except where the seasonal distribution of an anthropoid vector is the controlling factor. I do not think Dr. Short should feel badly for not having found the reason for the seasonal distribution of rheumatoid arthritis. I suspect that his hypothesis about seasonal variation in the host is likely to prove the most productive.

Dr. Russell L. Cecil (New York, N.Y.): What every rheumatologist would like would be what one could call an ad infinitum remission. Dr. Kammerer pointed out to me a patient with a history of Still's disease, who recovered, and then went for 25 years in remission before developing typical rheumatoid arthritis.

Dr. Charley J. Smyth (Denver, Col.): I want to congratulate this speaker, too, because this type of work can only be done by the directors of arthritic clinics.

Such men have a tremendous responsibility in settin some sort of base line for clinical evaluation, so that when problems come from the basic group to the cling we can make critical, reasonable, and valid deductions as physicians responsible for the care of patients. We have a great educational problem, for many doctors do not know the difference between rheumatoid arthritis and gout, or the variable nature of rheumatoid arthritis itself, and $I$ think the work of this group in Boston is putting a firm basis under some of the loose thinking and fuzzy definitions currently in use.

DR. SHORT: These patients were all carefully screened for gout. One must always think of gout in any form of intermittent arthritis.

I also agree with Dr. Cobb that the seasonal frequency of disease is a subject that might be explored further.

Physico-Chemical Investigation of Synovial Fluid.* By

ERNEST Fletcher, London, England (by invitation).

The term viscosity has been used loosely by many workers studying the rheological properties of synovial fluids. Although it is well known that synovial fluid exhibits flow anomalies due to the highly polymerized state of hyaluronic acid, measurements have usually been made in viscometers designed for simple fluids, often no precautions being taken to minimize errors due to its anomalous behaviour. Quantitative studies of this anomalous behaviour have only been made with instruments too complex for routine use.

By using a U-shaped viscometer (described by Scott-

- Most of the experimental work on which this paper is based was done by R. Markham, Esq., B.Sc., Biochemist to the Department of Rheumatism at the Royal Free Hospital, London, and Dr. P. O. Williams, Registrar to the Department. 
Blair) with a central horizontal capillary and vertical wide-bore side-arms, a study has been made of viscosity and the anomalies due to stress, capillary radius, and capillary length. This may be used to obtain readings in standard units, and it is possible by this method to compare viscosities directly, unhindered by the modifying effect of the rheumatic disease on synovial fluid.

Rheological measurements in synovial fluid studies should be standardized.

Difficulties are encountered in estimating hyaluronic acid glucosamine, the concentration of which must be known in calculating intrinsic viscosity. Intrinsic viscosity is used as a measure of the degree of mean polymerization of hyaluronic acid, and the figures obtained do not agree with the relative degrees of polymerization suggested by the mucin precipitate types produced by acetic acid.

Preliminary investigations indicate that it should be possible to obtain a measure of degree of mean polymerization and hyaluronic acid concentration from viscosity data alone.

Discussion.-Dr. David H. Kling (Los Angeles, Calif.): Dr. Fletcher and his group have made a valuable contribution. I want to express my thanks for their assistance in permitting us to introduce the Scott-Blair viscometer into our laboratory. We found it useful for the measurement of viscosity under changing conditions of shear. It has given a more accurate measurement of relative as well as of anomalous viscosity which is not possible with the Oswald type of viscometer.

Neurology of Osteo-Arthritis of the Cervical Spine. By EUGENE NeUWIRTH, Great Neck, N.Y.

The varied and complex neurological and neurovascular syndromes resulting from involvement of neural structures in the cervical region by degenerative changes involving the uncovertebral and/or apophyseal (interlaminar) joints are discussed. The pathogenic significance of the osteo-arthritic spurs which develop in the uncovertebral joints is far greater than that of the apophyseal joints.

The following nervous structures may be implicated through compression and irritation by arthritic proif erations in the cervical spine:

(1) cervical segment of the spinal cord;

(2) ventral and dorsal nerve roots;

(3) vertebral nerve;

(4) sympathetic plexus surrounding the vertebral artery;

(5) autonomic fibres passing through ventral roots C4 to C7.

The sensory, motor, reflex, vasomotor, and atrophic disturbances arising from involvement of the neural structures may give rise to the following syndrome:

Cervicobrachial neuralgia (radiculalgia),

Lower motor neuron syndrome,

Shoulder-hand syndrome ("neurotrophic rheumatism of the upper extremity"),

Ocular lesions including optic neuritis,

"Intricated" and pseudo-angina,

Headaches,
Facial pains ("atypical facial neuralgia"),

Syndrome of Barré-Lieou,

Syndromes resembling those of degenerative diseases of the spinal cord (multiple sclerosis, amyotrophic lateral sclerosis, etc.).

The cardinal point of the problem is the very important question: whether there is a causal relationship between the cervical osteophytic spurs and the neurological manifestations?

Osteophytes jutting into the spinal canal or the intervertebral and transverse foramina may traumatize their nervous contents and produce neurological disturbances. On the other hand, roentgenological evidence of cervical osteophytes does not necessarily imply that they are the cause of neurological complications. Though cluttered with large osteophytes, the cervical spine of persons over 50 years old are generally asymptomatic.

It is believed that, in conjunction with the mechanical factor of compression, an inflammatory factor, particularly an inflammatory oedema within the cord and nerve roots due to irritation of the surrounding soft tissues through osteophytic spurring, brings about neurological manifestations.

It should be borne in mind, however, that even a normal roentgenogram does not preclude root involvement. "Root-sleeve fibrosis" (Frykholm) may cause radicular symptoms and signs through angulation and constriction of the cervical nerve roots in patients with roentgenologically normal cervical spines. This observation could explain the cases in which the level of the pathological change responsible for the neurological abnormalities does not coincide with the level of the osteo-arthritic lesion.

Discussion.-DR. David H. KLING (Los Angeles, Calif.): Dr. Neuwirth should be congratulated for calling our attention to this very important group of common conditions which cannot be explained either roentgenologically or on the basis of a simple segmental pathology. When a patient with severe rheumatoid arthritis involving the cervical spine developed optic neuritis, neurological and ophthalmological consultants could not arrive at a conclusion as to the aetiology. Dr. Neuwirth's concept supplies a plausible explanation of this obscure complication and many other puzzling radicular symptoms connected with spondylitis.

Pathological Fractures during Cortisone and Corticotropin Therapy. By Paul H. Curtiss, Jr., William S. Clark, and Charles H. Herndon, Cleveland, Ohio.

The development of severe osteoporosis with pathological fractures is now a recognized hazard of prolonged treatment with cortisone. Such fractures have been reported, but principally in female patients of the post-menopausal age group. The fact that this complication is not predominantly influenced by age or sex is illustrated by four cases to be presented. These patients were males with typical rheumatoid arthritis whose ages ranged from 9 to 67 years, and who had received cortisone or corticotropin continuously or intermittently for periods of 1 to 4 years. Each developed vertebral fractures of varying extent and severity without known trauma. The precise role of cortisone or corticotropin 
in the genesis of the fractures could not be determined. Calcium, phosphorus, and nitrogen excretion is known to be increased during cortisone and corticotropin administration, during immobilization, and during the course of active rheumatoid arthritis. All these factors were present in these patients, but it is reasonable that hormone treatment was mainly responsible.

Although phosphorus, calcium, and nitrogen excretion is decreased by oestrogens, androgens, and physical activity, no therapeutic or preventive measures have been proved effective against pathological fractures of this type.

Discussion.-DR. EDWARd F. Rosenberg (Chicago, Ill.): I regret to say that this is a subject on which I am rapidly becoming well informed.

Compression fractures of the vertebrae, transverse fractures of the neck of the femur and fractures of the humerus, radius, ribs, and tibia, have occurred among our patients receiving hormone treatment for rheumatoid arthritis. Yet it is only fair to recall that during the pre-cortisone era fractures such as these were not unknown, also that osteoporosis is a cardinal feature of severe rheumatoid arthritis. I would say that the incidence of such fractures is higher now than before the use of hormones, but that the basis for them is the same as before the advent of this method of treatment.

I do not think this is any indictment of hormone therapy, and I am not in agreement with the recommendation that we are constrained to withdraw cortisone or ACTH if a fracture occurs. I prefer to institute proper treatment for the fracture and at the same time to continue treatment with the hormones.

I venture to predict that, should we be fortunate enough to develop the "ideal" therapy for rheumatoid arthritis, we should see even more fractures than we do now. The nature of this disease is such that when the patient becomes active he exposes his weakened skeleton to stresses beyond the tolerance of his fragile bones. In these circumstances fractures are inevitable.

The hope of bringing relief from the terrible suffering which accompanies rheumatoid arthritis should be sufficient to justify a calculated risk.

We may expect that resumption of normal activity may encourage restoration of strength to the atrophic skeleton. The problem may be solved for some of the patients in this indirect manner.

This is not a simple matter of loss of calcium through hormone treatment. Our studies showed no distinctive effect on calcium balance, and our patients' blood calcium levels have been consistently normal.

It has been suggested that we should avoid using this treatment if roentgenograms show any significant degree of osteoporosis, but this would bring great hardship in many cases, for those with skeletal atrophy include individuals who respond quite well to hormones, only a small percentage of whom will suffer a fracture. We may warn all patients with osteoporosis to avoid any unusual stress such as lifting heavy objects, but we must be prepared to encounter fractures from insignificant trauma, in the performance of acts which can hardly be avoided.

For the moment, it seems to me proper to proceed cautiously, to advise every precaution possible, but at the same time to press forward with our work in this field.

Dr. Curtiss : I should like to call on Dr, William Clark, my co-author, to speak about calcium excretion and the administration of hormones.

Dr. Clark: It is difficult to speak about cortisone complications without giving the impression that you are against cortisone. That is not the implication here.

Pathological fractures constitute one of the major complications of cortisone therapy. From metabolic knowledge accrued to date, it seems there are certain things that can be done to try to prevent them.

We are not presenting this paper, as Dr. Rosenberg implies, as an argument as to whether cortisone should be used or not. We are impressed because we saw all these patients within a short space of time, and we feel that the dosage of cortisone and not the disease was the major factor.

In 8 years at the Massachusetts General Hospital, I can only recall two patients with rheumatoid arthritis who developed pathological fractures, both of which occurred on the operating table in preparation for surgery. In the 18 months in Cleveland, we have seen six pathological fractures in patients on cortisone therapy. I think these patients were overdosed and that such indiscretions can result in pathological fractures of this degree. When such a complication occurs we find very little choice but to pull out of it and start all over again.

Occurrence of Spondylitis in Juvenile Rheumatoid Arthritis. By Theodore A. POTTER, ROBERT Barkin, and J. Sydney Stillman, Boston, Mass.

Spondylitis occurs more commonly in juvenile rheumatoid arthritis than was previously thought. In 61 cases there was clinical involvement in 70 per cent. and radioô logical confirmation in 54 per cent.

Clinical evidence is noted by loss of neck and spinat motion, developing round-back, and cervical spine extension deformity. Spinal $x$ rays show the following changes:

Fusion of apophyseal joints, lateral masses, and sacro-iliac joints;

Underdevelopment of vertebral bodies, intervertebral disks and spinous processes;

Occasional subluxation of the atlas on the axis;

Lack of paravertebral ligamentous calcification.

These changes can take place in as little as 4 months. The areas most commonly involved are the cervical and sacro-iliac joints, often with no evidence of disease in the intervening spine. The average age of onset was 9.8 years with a span of $2 \frac{1}{2}$ to 20 years. 81 per cent. of males and 65 per cent. of females were affected.

In a few cases $x$-ray evidence of spondylitis was the only stigma of Still's disease.

Conversely, this type of survey can be helpful in establishing a diagnosis where clinical involvement of peripheral arthritis is absent.

From the orthopaedic and medico-legal aspects where spinal injury has occurred, it is most important to distinguish between traumatic fusion, congenital failure of segmentation, and juvenile rheumatoid spondylitis.

Discussion.-Dr. Charley J. SMyth (Denver, Col.): Were there any subcutaneous nodules in any of these children?

DR. Morris ZIFF (New York, N.Y.): What is the 
usual order of onset of the arthritis? Am I right in presuming it to be peripheral?

Dr. Richard H. Freyberg (New York, N. Y.): I congratulate the authors for clarifying what has been vague in the minds of many of us.

For sometime we have been seeing arthritic children with stiff necks, and thought this was caused by extraarticular rheumatism. The development of these changes indicates that many of these children have arthritis of the cervical spine. It is to be emphasized that this has quite a different type of arthritis from that seen in rheumatoid (ankylosing) spondylitis of adolescents and adults.

Some roentgenologists who see the $x$-ray films are unfamiliar with this form of arthritis, and send in misleading reports that the condition is due to congenital fusion of the spine.

DR. POTTER: In answer to Dr. Ziff's question on the order of onset, I presume that in most of these children the involvement of the peripheral joints preceded that of the spine, although it is possible that a child might have a backache for 2 or 3 months before any peripheral joint pain was noticed. We have seen that in adults with rheumatoid arthritis.

I cannot answer the question about subcutaneous nodules, but I am sure they occur.

I want to thank Dr. Freyberg for his remarks. Congenital fusion of the vertebral bodies or so-called congenital failure of segmentation present an important problem of differential diagnosis.

In congenital fusion the dorsal and cervical regions are most often affected, two contiguous vertebrae form one mass, with no evidence of disk, the striations of bone going between the bodies, the posterior elements are fused in one mass, with one large spinous process, and there is no underdevelopment of the area. With these points in mind, perhaps our radiologists could do better.

Mechanism of Anaemia associated with Rheumatoid Arthritis. By E. J. Freireich, J. F. Ross (by invitation), T. B. BAYLES, C. P. EMERSON, and S. C. FINCH (by invitation), with the technical assistance of Miss C. MacDonald, Boston, Mass.

A moderate anaemia refractory to anti-anaemic therapy is commonly found in active rheumatoid arthritis. We have studied:

(1) red blood cell production, utilizing radioactive iron tracer techniques;

(2) red blood cell destruction by faecal urobilinogen measurements;

(3) red cell survival with the Ashby technique of differential agglutination.

(1) An injected tracer dose of radio-iron was rapidly removed from the plasma of these patients. The serum iron concentration, however, was depressed so that the calculated iron turnover rate was within the normal range. External monitoring over major body organs showed that the largest fraction of radio-iron cleared from the plasma was deposited in the bone marrow and subsequently discharged into the blood. 80 to 95 per cent. of the injected radio-iron was utilized for red cell formation in 7 to 10 days. Thus the rate of red cell formation was within the normal range.

(2) The quantity of haemoglobin destroyed per day, as calculated from faecal urobilinogen measurements, was within the normal range.

(3) Normal donor cells transfused into rheumatoid arthritis patients showed a decrease in their effective lifespan. In contrast, red cells from rheumatoid arthritis patients transfused into normal recipients survived normally. Thus these patients produce a red cell capable of normal survival, but may have an extracorpuscular haemolytic system not associated with any identifiable immune mechanism responsible for a decrease in the lifespan of red cells.

Although these patients had a normal rate of erythropoiesis, the shortened red cell survival resulted in a decreased red cell mass. The marrow fails to increase its rate of red blood cell production.

Discussion.-DR. Joseph J. Bunim (Bethesda, Md): Dr. Bayles and his associates are to be congratulated for this very well conceived and admirably executed study. It is encouraging to report that our results of work done mainly by Dr. Frank Ebaugh, Jr., and Dr. Ralph Peterson are essentially in agreement with theirs.

There is one slight difference, however, that may perhaps be resolved with further studies and more patients. We have transfused the red blood cells from two patients with rheumatoid arthritis into two separate normal recipients. In one case the survival time was normal in the recipient, although it was abnormally short in the patient. But in the second case, when the cells were transfused to the normal recipient, the rate of destruction was unaltered, i.e. it was just as abnormally high as in the patient. That may have been because some substance responsible for the destruction was so firmly attached to the transfused red blood cell as not to be separated, despite repeated washing.

I think the important ground of agreement is that the anaemia seen in rheumatoid arthritis is not an iron deficiency anaemia, but results from increased destruction without adequate compensatory production.

In a diagram of our results the rate of cell destruction compared with the normal is represented by a red column. This rate was determined by survival time, not by the Ashby selective agglutination technique used by the Boston group, but by tagging these cells with radioactive chromium.

Having determined the rate of destruction and knowing the red blood cell mass in the patient, the rate of production was calculated. A green column shows this rate of production compared with normal. In three patients with active rheumatoid arthritis the rates of destruction and production were essentially the same, so that they had an almost normal haematocrit of 42,42 , and 42 .

In almost every case of active rheumatoid arthritis (eleven patients), the rate of destruction is greater than normal, but the rate of production does not rise adequately. As a result, anaemia develops and the haematocrit falls to 35,31 , and 34 .

One particular patient had a mild bout of arthritis and the rate of production of cells was almost as rapid as the rate of destruction. Suddenly, without known cause, he had a severe spontaneous exacerbation. The rate of destruction rose to twice normal, and the rate of production was unable to keep up with it. Within 2 months the haematocrit fell from 42 to 34 , and we know that there was no blood loss.

A second patient showed the opposite effect. She entered the hospital in a very severe and active rheumatoid 
state, the rate of destruction being three times the normal. The rate of production was only twice the normal, with a resulting anaemia and a haematocrit of 24 . Then the rheumatoid activity subsided without any specific medication, and although the rate of destruction was still twice the normal, the rate of production was also about twice the normal, so that the haematocrit rose to 40 .

Dr. A. St. J. Dixon (Boston, Mass.): Dr. Freireich and Dr. Bayles have clearly shown, as Dr. Bunim and his colleagues have also shown, that decreased red cell survival is a factor in the production of the anaemia of rheumatoid arthritis in some cases.

We, on the other side of Boston, wondered how far this anaemia was due to increase in plasma volume or to decrease in red cell mass. We took a series of ten typical rheumatoid arthritis patients, all women, between the ages of 35 and 65 and matched them as closely as we could with ten normal women. We measured the plasma volume by the Evans blue method, and simultaneously measured the red cell mass by the radioactive sodium chromate red cell tagging method (Sterling and Gray, 1950).* Ten of the patients and eight of the normal subjects were confined to bed at the time of the test. As expected, the ten rheumatoid patients showed an increased proportion of plasma to red cell mass, and, were hence more anaemic than the normal controls, but, to our surprise, most of this decrease in haematocrit was due to a 22 per cent. increase in the absolute plasma volume which was statistically significant (Table). A 5 per cent. decrease in red cell mass was not significant. There was also a significant increase in total blood volume.

\begin{tabular}{|c|c|c|c|}
\hline \multirow{2}{*}{ Subjects } & $\begin{array}{l}\text { Ten Normal } \\
\text { Women }\end{array}$ & $\begin{array}{l}\text { Ten Arthritic } \\
\text { Women }\end{array}$ & Difference \\
\hline & 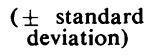 & $\begin{array}{c} \pm \text { standard } \\
\text { deviation) }\end{array}$ & $(\div \underset{\text { error })}{\text { standard }}$ \\
\hline $\begin{array}{l}\text { Plasma Volume } \\
\text { (ml. per sq. m.) .. }\end{array}$ & $1,452 \pm 110$ & $1,767 \pm 204$ & $314 \div 73 *$ \\
\hline $\begin{array}{l}\text { Red Cell Mass } \\
\text { (ml. per sq. m.) .. }\end{array}$ & $926 \pm 71$ & $868 \pm 110$ & $-58 \div 132$ \\
\hline $\begin{array}{l}\text { Blood Volume } \\
\quad \text { (ml. per sq. m.)... }\end{array}$ & $2,379 \pm 134$ & $2,636 \pm 232$ & $257 \div 86^{*}$ \\
\hline
\end{tabular}

One trouble in making comparisons between patients and controls arises in choosing the standard of references by which they are compared. We have used surface area here. To have used body-weight would have introduced an error because the normal blood volume per unit weight increases as weight decreases, and our patients were significantly less heavy than the controls. Estimates of surface area, however, depend on height, and we had difficulty in measuring height in patients who had flexed knees and in others who were confined to bed. Consequently, I have recalculated these figures, assuming an average underestimate of height of 2 inches. Even this does not affect the validity of these results. The plasma volume is still significantly increased, and the difference in red cell mass does not reach significance.

It seems, therefore, judging from these figures, that the anaemia of rheumatoid arthritis is at least partly due to increase in plasma volume, but I must emphasize the need for caution in extrapolating from one series of

\footnotetext{
* Sterling, K., and Gray, S. J. (1950). J. clin. Invest., 29, 1614.
}

selected patients to the population of rheumatoid arthritis as a whole. Other contributing factors such as $\overline{3}$ decreased red cell survival are by no means excluded.

DR. BAYles: In answer to Dr. Bunim: the sicker patients are more apt to show increased red blood cell $\overrightarrow{\vec{F}}$ destruction.

In answer to Dr. Dixon, the plasma volume of sick people is generally hydraemic and this certainly plays a $\frac{\mathrm{C}}{\mathrm{O}}$ part. We feel that there is a curious mechanism here, $\overline{\bar{c}}$ in that the patient, or rather his bone marrow, does not $\vec{\nabla}$ have the ability to respond to the lowered red cell mass.

Action of Uricosuric Agents on Discrete Renal Functions, with special reference to Effects on Uric Acid Excre-? tion in Gout. By Alexander B. Gutman, Jonas H. $\overrightarrow{\vec{\omega}}$ Sirota, and T. F. Yü, New York, N.Y.

Better insight into the mechanisms of action of uricosuric drugs is desirable because of their current use in the management of gouty arthritis. The present report $\vec{\omega}$ summarizes acute and protracted renal clearance studies during probenecid, phenylbutazone, and salicylate therapy in gouty subjects.

Probenecid in a daily oral dosage of $1 \mathrm{~g}$. increases theo mean urinary urate excretion by approximately 50 per $_{\rightarrow}$ cent., with corresponding falls in serum urate. This is $\square$ due to a sharp increase in $C$ urate $/ C$ inulin occurring $\mathbb{C}$ within 40 minutes after one $2-\mathrm{g}$. oral dose, reaching aథ mean 4-fold peak in about 2 hours, and persisting about

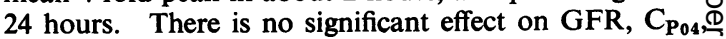
$\mathrm{C}_{\mathrm{K}}$; sometimes a slight increase in $\mathrm{C}_{\mathrm{Na}}$ and $\mathrm{C}_{\mathrm{C}_{1}} ; \mathrm{C}_{\mathrm{PAPH}}$ is depressed.

Phenylbutazone has a uricosuric effect only at blog $\mathrm{d}^{\circledR}$ levels $>10 \mathrm{mg}$. per cent. After intravenous inject得? (12-27 mg./Kg.), C urate/C inulin rose within 2 hours.tos a mean 3-fold peak, uricosuria persisting about 24 hours $\frac{}{\sigma}$ GFR unchanged or lowered; $\mathrm{C}_{\mathrm{PAH}}, \mathrm{C}_{\mathrm{Na}}, \mathrm{C}_{\mathrm{Cl}_{1}}$ wer@ depressed; $C_{K}$ was unaffected. After oral adminis $\frac{0}{\mathbb{D}}$ tration, uricosuria usually occurred but was variable in onset and magnitude.

The renal effects of salicylate are more complex Plasma salicylate levels $>5 \mathrm{mg}$. per cent. lower $\mathrm{C}$ urate $E_{E}$ $C$ inulin; levels $>12 \mathrm{mg}$. per cent. cause a mean peak $3 \frac{1}{2}$ fold rise in $C$ urate/C inulin, of short duration intermediate plasma salicylate levels have little or noक effect. Concomitant bicarbonate infusion increases $\mathrm{C}$ urate without affecting $\mathrm{C}$ inulin when urinary $\mathrm{pH}>7 \cdot 5 ?$ and excreted salicylate exceeds filtered salicylate, sug gesting tubular secretion of salicylate.

Probenecid is best tolerated clinically in oral doses and is the most potent and selective uricosuric agent examined.

Discussion.-Dr. E. R. Huffman (Denver, Col.): should like to show the salient features of our results using oral phenylbutazone.* The serum and urine urate after 8 days' oral administration of phenylbutazone ion gouty and non-gouty arthritics, showed a maximunes decrease of $3.6 \mathrm{mg}$. (42 per cent.). The non-goutb subjects had a smaller decrease $(2 \cdot 4 \mathrm{mg}$.), but the percent tage change was the same (42 per cent.).

The urinary urate in gouty subjects showed a meand increase of $204 \mathrm{mg}$. per $24 \mathrm{hrs}$ above the control valuẹ

\footnotetext{
* Full article on p. 317 of this issue.
} 
compared with $69 \mathrm{mg}$. per $24 \mathrm{hrs}$ in the non-gouty subjects.

One gouty patient and two non-gouty patients had a mean decrease in the urinary urate while under therapy; in spite of a decreased output, they averaged a $1 \mathrm{mg}$. per cent. decrease in serum urate. All three subjects showed marked fluid retention. Our observations for the gouty subjects were significant.

When our data on the effect of 8 days' oral administration of phenylbutazone on the serum urate and renal clearance of urate was summarized, we found the clearance in the gouty subjects increased by $9.5 \mathrm{ml}$. (177 per cent.), and that of the non-gouty subjects by $8.3 \mathrm{ml}$. (115 per cent.). The clearance ratio $\frac{c_{u r}}{c_{c r}}$ showed an increase of 257 per cent. in the gouty and 115 per cent. in the non-gouty subjects.

Those with phenylbutazone levels below $10 \mathrm{mg}$. per cent. showed an increase in the clearance ratio, $\frac{C_{u r}}{C_{c r}}$ of only 48 per cent., while those with serum levels above $10 \mathrm{mg}$. per cent. showed an increase of 346 per cent.

Serum phenylbutazone levels were also determined in 73 instances after 8 days' oral administration; each increment in dosage up to and including $600 \mathrm{mg}$. per $24 \mathrm{hrs}$ produced a marked increase in the serum phenylbutazone level compared with the effect of similar increments above $600 \mathrm{mg}$. For example, increasing the phenylbutazone dosage from 200 to $600 \mathrm{mg} . / 24 \mathrm{hrs}$ resulted in an increase in the serum level of $7 \cdot 2 \mathrm{mg}$. (115 per cent.); a similar increase in dosage from 600 to 1,000 $\mathrm{mg} . / 24 \mathrm{hrs}$ resulted in an increase of only $2.5 \mathrm{mg}$. (10 per cent.).

Ten out of thirteen subjects receiving $600 \mathrm{mg}$. daily, and all who received dosages above this amount, showed serum levels above $10 \mathrm{mg}$. per cent.

These data indicate that orally administered phenylbutazone is a uricosuric agent. It is noteworthy that in three out of nineteen subjects the serum urate level decreased, while the urinary urate level remained steady. All manifested a marked weight gain and other findings associated with fluid retention.

Dosages of $600 \mathrm{mg}$. or above are necessary to produce serum phenylbutazone levels greater than $10 \mathrm{mg}$. per cent., and serum levels above $10 \mathrm{mg}$. per cent. are necessary to produce a marked uricosuric effect.

Dr. William H. Kammerer (New York, N.Y.): Dr. Gutman, I wonder if your group has been able to study the effect of Benemid in any of the siblings of patients with clinical gout who may also have hyperuricaemia.

Dr. Gutman: I should like to thank Dr. Huffman for this additional data.

In answer to Dr. Kammerer: we have not given Benemid to asymptomatic siblings of gouty subjects. We should expect that anyone with hyperuricaemia would show a similar response, whether presenting clinical symptoms or not.

Intravenous Colchicine in the Management of Gouty Arthritis. By Wallace Graham and James B. RoBerts, Toronto, Canada. (Paper read by Dr. Donald C. Graham.)

The intravenous administration of colchicine is worthy of a much wider application where a rapid response is required and where severe gastro-intestinal intolerance prohibits oral medication.

Colchicine was administered intravenously to 41 patients suffering from acute gouty arthritis. The majority experienced a rapid and dramatic relief from pain within 4 hours. No toxic reaction was observed after a single dose of $3 \mathrm{mg}$., but after repeated administration gastro-intestinal manifestations may occur.

Intravenous colchicine has proved to be a safe, rapid, and effective weapon in the acute phase and deserves much wider recognition. The administration is a simple office or home procedure. The prophylactic and therapeutic value of the intravenous route in surgical patients should be noted.

Phenylbutazone (Butazolidin) was also used orally and intramuscularly.*

Discussion.-Dr. William H. Kammerer (New York, $N . Y$.): We have used intravenous colchicine for the past 15 years in our practice and have found it a very efficacious agent in the treatment of the acute attack. Over and above that, however, I think it has another advantage, and that is as a therapeutic test in a patient with an acute monarticular synovitis, particularly in the male. Here it may help in diagnosis because, as Dr. Graham has pointed out, the results from colchicine are rather specific and, in a large percentage of cases, positive. It offers an obvious advantage over phenylbutazone.

Dr. Charley J. Smyth (Denver, Col.): I should like to congratulate our essayists for a most delightful review of the historical aspect of this subject.

We have had some experience in the last 3 years with phenylbutazone given by oral doses, ranging from 100 to $200 \mathrm{mg}$. in acute gout. In every instance, in thirty acute attacks in 27 different patients, we have had complete abortion of the acute attack within 8 hours. None of these patients had any particular change in the serum uric acid level at the end of 8 hours, and we had no significant toxicity.

We think that the oral use of Phenylbutazone holds considerable promise.

Dr. Howard F. Polley (Rochester, Minn.): Drs Ward, Slocumb, Hench, and I wish to confirm Dr. Graham's report on the effectiveness of colchicine administered intravenously for acute gouty arthritis. We have given several hundred injections with satisfactory and encouraging results. The preparation and its method of administration are well tolerated. In most instances only a single injection is needed; rarely are more than two doses required. We have generally used doses at least as large as those given by Dr. Graham and his associates. Occasionally larger doses, up to $5 \mathrm{ml}$. and even up to $10 \mathrm{ml}$. in selected cases (colchicine $0.65 \mathrm{mg} . / \mathrm{ml}$.), have been used. Even these doses have been well tolerated except for the infrequent occurrence of temporary gastro-intestinal upset when the large doses were given. I believe that none of our patients had nausea, vomiting, or diarrhoea from doses of $3 \mathrm{mg}$. or less, such as those used by Dr. Graham. One patient has had more than 100 doses of 5 to $10 \mathrm{ml}$. each over a period of 2 to 3 years without signs of intolerance or refractoriness to colchicine.

We have found the intravenous preparation of colchicine especially suitable for post-operative attacks of gouty arthritis. The risk of gastro-intestinal upset from the oral use of colchicine generally is so great that

* See also Annals of the Rheumatic Diseases (1953). 12, 16. 
surgeons and physicians are unwilling to give it by mouth after operations.

In so far as I am aware, a preparation of colchicine for intravenous administration of this concentration is not on the market in this country. Our supply is made in the laboratories at the Mayo Clinic from pure crystalline colchicine obtained from Abbott Laboratories. I should like to ask Dr. Kammerer or the other discussers who have used colchicine intravenously where they obtained their preparations. Perhaps members of our society could individually or even collectively encourage our friends in the pharmaceutical industry to make a preparation of colchicine suitable for intravenous use generally available to the medical profession. I think such an effort would benefit our patients with gouty arthritis.

DR. JACOB S. Kominz (Rochester, N.Y.): In answer to Dr. Polley, I represent no drug house, but Parke Davis sent me a big supply of $1-\mathrm{ml}$. ampoules containing $1 \mathrm{mg}$. colchicine. I have been using this for over a year now, with results similar to those described by Dr. Graham and Dr. Polley.

Dr. William H. Kammerer (New York, N.Y.): The preparation of colchicine just mentioned is the one we used. I should like to utter a word of caution because there is also another preparation on the market (I have forgotten which drug house puts it up) in combination with 20 gr. sodium salicylate and 10 gr. sodium iodide. If you are using it for a therapeutic test, the $20 \mathrm{gr}$. salicylate may lead you a little astray.

Dr. Dwight C. Ensign (Detroit, Mich.): I just want to confirm Dr. Kominz's statement that Parke Davis does have this preparation available. As I understand it, in a roundabout way, they were about to advertise it to the profession when ACTH and cortisone came out, and they then felt it was a poor time to launch another new drug. If anybody is interested in getting it, if they will address their sales manager, it will promptly be made available. We also received a gratis supply of this material, which they were about to market under the name of "Aqua-Colchin".

Dr. Howard F. Polley (Rochester, Minn.): We have also received some of the colchicine prepared for intravenous use by Parke Davis. It has been said that they (and other companies) estimate that the cost of producing this item for general distribution would be greater than the cost of making it available as an unlisted item to those physicians who request it. In all probability, however, the intravenous use of colchicine would become more widespread if the availability of a suitable preparation were more generally known.

Dr. Richard T. Smith (Philadelphia, Pa): At the last count before I left home, we had used phenylbutazone instead of colchicine in seventy acute attacks.

When we first started using it we gave $400 \mathrm{mg}$. immediately, $200 \mathrm{mg}$. in 2 hours, and $200 \mathrm{mg}$. in another 2 hours, and the majority of the patients received benefit within 8 to 10 hours. More recently we tried to decrease the dose to half the amount, and the majority of patients have responded to that, but three or four needed the full dose. It is a good general substitute for colchicine, but one patient who failed to respond to phenylbutazone gets good results from colchicine.

Dr. Donald Graham: All I want to do, sir, is thank those who discussed this paper.
Clinical and Laboratory Effect of Long-Term Intra® Articular Hydrocortisone in Rheumatoid Arthritiș By Ivan F. Duff, William M. Mikkelsen, Willia D. Robinson, and Noel H. Chatelin, Ann Arbow? Michigan.

Over a 3-year period, 1,020 serial injections of 37-5 $\overline{\overline{0}}$ mg. hydrocortisone have been made into 105 rheumatoid joints (sixty patients). In 53 joints (50 per cent.) worth while benefit was achieved; in ten knees the injection were combined with orthopaedic measures to overcomo flexion contractures. In fifteen other joints benefit was eventually prolonged for 17-34 days before a repeact injection was required. Upon discontinuation of therapy, benefit has persisted from 4-12 months in 19 per. cent. of all treated joints. In twelve knees (seve $\overrightarrow{\mathrm{Bu}}$ patients) local remission of active inflammation accom? panied improvement in untreated joints, but control of the arthritis in the knees of two patients, with maintenance of weight-bearing, may have contributed to rapiôj hip-joint deterioration.

Treatment of 32 joints ( 31 per cent.) was eventuall w discontinued because partial initial benefit could not beे further improved. Decreasing local responsiveness to the steroid was observed in four joints. In twenty joints (19 per cent.) there was no clinical response to hydro cortisone. Ten individuals refused repeated injection $\$$ because of discomfort or failure to achieve benefit.

Synovial fluid from 35 knees was repeatedly studied As previously reported, local hydrocortisone may produce remarkable alterations toward normal in joint fl\&sdco These changes generally parallel the clinical effect $\bar{\beta}$ un dissociation was apparent in 29 per cent. Maintena of joint fluid improvement was usually dependent up repeated steroid injection. The alterations in synovias fluid were followed in seven joints from the active inflam $\overline{0}$ matory stage into remissions developing during the months of hydrocortisone administration and which have persisted for upwards of 16 months after steroid with drawal.

Discussion.-DR. JOSEPH L. Hollander (Philadelphia $\mathrm{Pa}$ ): Several points in this excellent paper bring out some. things we have been interested in for years.

One is this matter of the optimum dose. Dr. Duff and $\bar{E}$ Dr. Robinson have worked out, as we have, that thes optimum dose is between 25 and $37.5 \mathrm{mg}$. As Dr 3 . Dougherty demonstrated in his connective tissue work there is an optimum dose level. Too much can give nof only no greater response but even a diminished response? We have seen that, too. Perhaps Dr. Duff has seen such? over dosage and may want to describe it.

Secondly, the matter of decreasing effectiveness from $t$ repeated injections. We have seen that, too. We havefound that in such cases a change to hydrocortisonen tertiary-butyl acetate will often renew the effectiveness of the hydrocortisone acetate.

Thirdly, this matter of injections producing damage to the joints. Dr. Duff reported two or three patientsw who had been kept ambulatory by this method and then developed increasing degeneration in the hip joints. We have also seen that in a few cases. We have also followede quite a few of the knee cases by $x$ ray to see how much increase in damage there was, or whether osteoporosis was produced by this method, as it often is by large doses 
systemically. We have not seen osteoporosis produced by intra-articular hydrocortisone.

Lastly, the matter of relapse and sustained benefit. We feel there is some sustained benefit even when we discontinue the hydrocortisone injections in many cases. But we feel the method is most useful as an aid to facilitating rehabilitation, maintaining function, and making orthopaedic correction of deformities more rapid and effective.

Dr. DufF: The optimum dosage of intra-articular hydrocortisone is not very adequately defined. Observations reported in this study indicate that serial injections of hydrocortisone acetate at the 10-mg. level are capable of achieving definite improvements in synovial fluid characteristics, but without obvious clinical benefit. Repeated dosages at the $25-\mathrm{mg}$. level have been associated with clinical benefit as well as favourable joint fluid alterations. Dosages in the $25-$ to $50-\mathrm{mg}$. range are routinely employed for intra-articular injections in our clinic. There is no evidence to our knowledge that dosages in excess of $50 \mathrm{mg}$. offer any particular advantage.

\section{Attempt to produce Experimental Arthritis with Synovo-}

Toxic Antiserum tagged with $\mathbf{I}^{131}$. By CuTting B.

Favour, Joel C. Goldthwait, and Theodore B.

BAyles, Boston, Mass.

Interest in the Masugi type of experimental nephritis which has been successfully studied with isotope-tagged antisera prompted this investigation of arthritis. Normal guinea-pigs were exsanguinated and their carcases perfused with saline. Pooled synovial tissue from several animals was extracted with saline buffered at different $p \mathrm{H}$ levels and the cell-free supernatants used to produce an anti-joint serum in rabbits. "Immune" rabbit plasma was fractionated by Cohn's cold alcohol technique and the various fractions tagged with $\mathbf{I}^{131}$. These were then injected into normal guinea-pigs. At various intervals between a few hours and 3 weeks animals were killed and the radioactivity of joints and various organs determined. Other animals were held for observation during longer intervals. Analysis of tissue samples, of local histology, and of surviving animals indicates that no damage or specific localization of an isotope tag on the joint tissue took place. Since care was taken to repeat for joint tissues that which can be done for nephritis, some doubt is cast on the specificity of the experimental nephritis model. Of more importance, no evidence has been found that arthritis is the result of an antibody directed against joint tissue.

Discussion.-Dr. J. Albert Key (St. Louis, Mo.): We have started some experiments similar to the first group without tagging our joint antigens. Those experiments will be dropped as soon as I get home because I think the authors have proved that one cannot sensitize an animal with joint tissue and then inject joint tissue into the circulation and produce inflammation in the joints.

I have been interested for quite a long time in trying to produce an Arthus-phenomenon in a joint. We used egg albumen and horse serum, or dog serum, rather. We produced a transient arthritis just as has been shown, but as soon as the acute inflammatory reaction subsided the joint tended to return to normal, unless irreversible changes had occurred. 